\title{
Fabrication of Nitrogen Donor Macro- and Meso-porous Materials for Group 11 Metal Ions Sorption
}

\author{
Kelebohile Mphanje, Orpah Zinyemba* (iD) and James Darkwa \\ Department of Chemistry, University of Johannesburg, Auckland Park Kingsway Campus, Auckland Park, 2006, South Africa.
}

Received 23 January 2017, revised 25 June 2018, accepted 20 July 2018.

\begin{abstract}
Macro(meso) porous polymer materials were prepared via a modified TIPS method using reagent grade polymers mixtures; polyacrylonitrile (PAN) and polyvinylpyridine-co-styrene (PVPS). Reaction conditions such as concentration, temperature and the solvents used were found to affect the morphology of the polymer materials formed. The use of low heat for polymer dissolution, near critical point polymer concentration and a miscible solvent/non-solvent pair in excess non-solvent were found to produce porous polymers. The macro-(meso-) porous materials were further used in metal adsorption/desorption studies and they were found to remove up to $80 \%$ of $\mathrm{Cu}(\mathrm{II}), \mathrm{Ag}(\mathrm{I})$ and $\mathrm{Au}(\mathrm{III})$ from aqueous solution. Adsorption/desorption experiments were performed using the polymer monolith KSP1 $\left\{\right.$ (PAN : PVPS = $75: 25(\mathrm{w} / \mathrm{w})$ in DMSO : $\left.\mathrm{H}_{2} \mathrm{O}=90: 10(\mathrm{v} / \mathrm{v})\right\}$ and it showed excellent reusability adsorbing and desorbing up to $90 \%$ of the metal ions in a series of five cycles. Ternary solutions for adsorption/desorption experiments were added in the order $\mathrm{Cu}(\mathrm{II}), \mathrm{Ag}(\mathrm{I})$ and $\mathrm{Au}(\mathrm{III})$.
\end{abstract}

KEYWORDS

Fabrication, polymer monolith, polyacrylonitrile, polyvinylpyridine-co-styrene, adsorption of group 11 metal ions.

\section{Introduction}

Metal ions in solutions of industrial effluents, as well as those found in acid mine drainage, pose environmental threat when such solutions find their way into water bodies. In order to prevent these metal ions from contaminating the environment and allowing for their remediation, adsorbents that can effectively bind these metals need to be developed. Potential sources of adsorbents are polymers that have monolithic structures having affinity for different metal ions. ${ }^{1}$ If successfully fabricated into monolithic structures, such polymer-sorbents are expected to have both high adsorption and desorption rates so as to allow for recycling of both the metal ions absorbed and the polymers. Successful fabrication of such polymer-sorbents would pave the way for investigating the ability of these polymers being employed as reusable materials for wastewater cleaning.

The synthesis of porous materials conventionally involves the use of either organic or inorganic templates, with the intention of controlling their physical and chemical properties. The attractiveness of such porous materials as sorbents has grown immensely within the past few decades owing to their versatility and myriad applications, ranging from biological to industrial. ${ }^{2-4}$ Non-solvent induced phase separation (NIPS) forms the basis to fabricate required sorption materials, which usually result in mesoporous materials. ${ }^{5-7}$ In fabricating mesoporous materials, Dong et al. ${ }^{7}$ and Tan et al. ${ }^{8}$ have established solvent (S) to nonsolvent (S/NS) ratios that favour fabrication of monolithic structures that can act as good sorbents. ${ }^{5}$ This fabrication method leads to materials with a high affinity for metal ions, high surface area and excellent sorbent properties.

Polymers with donor atoms have been investigated as sorbents for absorbing metal ions for nearly two decades. ${ }^{6}$ In using polymers that carry donor atoms to fabricate sorbent materials to absorb metal ions, thermally induced phase separation is one of the effective methods to fabricate such polymers. ${ }^{5,6}$ The Uyama

* To whom correspondence should be addressed. E-mail: ozinyemba@uj.ac.za group has used NIPS to fabricate a number of macro- and mesoporous materials from polyvinylacrylonitrile (PAN) that act as ion exchange material. ${ }^{8}$ Uyama and co-workers employed amidoxated PAN monoliths to clean wastewater. Such material has an added advantage of having both macro- and mesoporous pores that result in high flow-throughput property as metal ion exchangers.

In the present study we have used for the first time the Uyama approach to fabricate novel marco-and mesoporous monoliths from polyacrylonitrile (PAN), polyvinyl-4-pyridine (PVP) and polyvinyl-4-pyridine-co-sytrene (PVPS) as sorbent materials and investigated their absorption capacity for group 11 metal ions that are typical base metals found in mining effluents. This paper is a pilot study aimed at eventually determining the effectiveness of the above-mentioned polymer monoliths as recyclable adsorbents for purification of water in the Mpumalanga region. The water quality in the Mpumalanga province of South Africa has been a cause for concern in South Africa for almost two decades. ${ }^{9-10}$ Acid mine drainage from coal mining is a problem in the Highveld coalfield in Mpumalanga. This problem has received media attention as a result of severe pollution observed in the Loskop Dam as well as the Olifants River catchment where water is contaminated by base metals and other effluents. ${ }^{11,12}$ This has resulted in depletion of aquatic life, disruption of the food chain, contamination of portable water owing to the heavy metals dissolved in the drinking water and deterioration of ecosystems. ${ }^{10}$

In this preliminary study, only results from sorption/desorption studies using standard solutions are reported aimed at highlighting the potential these monolithic materials possess in acting as reusable sorbents for group 11 metals. The recovery of precious metals such as gold and silver, even at very low concentrations, is something that can potentially be of economic value. Our future communication is intended to include analysis of real samples hence this communication serves as proof of concept only. We report our preliminary findings in this paper. 


\section{Experimental}

\subsection{Chemicals and Reagents}

Polyacrylonitrile (PAN) $\left(\mathrm{M}_{\mathrm{w}} \sim 150000\right)$ and polyvinylpyridineco-styrene (PVPS) $\left(\mathrm{M}_{\mathrm{w}} \sim 220\right.$ 000) were purchased from Sigma Aldrich (Johannesburg, South Africa) and used as received. Analytical grade dimethyl sulfoxide (DMSO), dimethyl formamide (DMF), $25 \% \mathrm{NH}_{4} \mathrm{OH}, 85 \%$ glacial $\mathrm{CH}_{3} \mathrm{COOH}$ and methanol were purchased from Rochelle Chemicals (Johannesburg, South Africa). Milli-Q $\mathrm{H}_{2} \mathrm{O}$ used was purified using $18 \Omega \mathrm{cm}^{-1}$ millipore system by Merck (Johannesburg, South Africa).

\subsection{Instrumentation}

Pore sizes in macro- and meso-porous monoliths were determined using a Tuscan Vega3LMH Scanning Electron Microscope (SEM) at $8 \mathrm{kV}$ and working distance ranging from $30-5 \mathrm{~mm}$. Pore size distributions and surface area for the samples were determined by conducting isothermal Brunaer-Emmet-Teller (BET) $\mathrm{N}_{2}$-physisorption using a Micromeritics Tristar 3000. Differential scanning calorimetry (DSC) and thermogravimetric analyses (TGA) experiments were conducted on macro- and mesoporous monoliths to determine whether any of these composite materials had taken any new properties from the parent polymers. This was done using a Mettler Toledo DSC822 and TA Q500 TGA thermal analyzer. Metal uptake by monoliths was determined using an Analitikjena ContrAA 700 Graphite furnace instrument (Germany).

\subsection{Preparation of Macro- and Meso-porous Monoliths}

In a typical experiment $0.081 \mathrm{~g}$ of PAN was dissolved in a $10 \mathrm{~mL}$ mixture of $(90: 10 \mathrm{v} / \mathrm{v})$ of DMSO and Milli-Q water. The mixture was heated at $80^{\circ} \mathrm{C}$ until it became a clear homogeneous solution $(c a .6 \mathrm{~h})$. The solution was rapidly cooled on attaining homogeneity in a liquid nitrogen bath, resulting in the formation of a white solid and left in $500 \mathrm{~mL}$ of Milli-Q water for $2 \mathrm{~h}$ with stirring to aid solvent or non-solvent exchange. This process was repeated three times before the sample was isolated by decanting and the solid material washed with small aliquots (ca. $50 \mathrm{~mL})$ methanol and dried in vacuo, leading to spherical materials as the final product. Table 1 is a summary of polymer and solvent ratios that were used in fabricating polymer monoliths. All experiments were repeated at least three times.

\subsubsection{Polyacrylonitrile (PAN)}

For PAN 1, 2 and 4, different ratios of DMSO and water were used whilst for PAN 3, DMF was used in place of DMSO in a
Table 1 Fabrication of PAN and PAN-PV4P monoliths under different solvent conditions.

\begin{tabular}{ll}
\hline Polymer monolith & Solvent ratio \\
\hline PAN1 & DMSO $: \mathrm{H}_{2} \mathrm{O}=88: 12(\mathrm{v} / \mathrm{v})$ \\
PAN2 & DMSO $: \mathrm{H}_{2} \mathrm{O}=90: 10(\mathrm{v} / \mathrm{v})$ \\
PAN3 & DMF $: \mathrm{H}_{2} \mathrm{O}=90: 10(\mathrm{v} / \mathrm{v})$ \\
PAN4 & DMSO $: \mathrm{H}_{2} \mathrm{O}=95: 5(\mathrm{v} / \mathrm{v})$ \\
KPV1 $\left(88 \mathrm{mg} \mathrm{mL}^{-1}\right)$ & DMSO $: \mathrm{H}_{2} \mathrm{O}=90: 10(\mathrm{v} / \mathrm{v})$ \\
KPV2 $\left(110 \mathrm{mg} \mathrm{mL}^{-1}\right)$ & DMSO $: \mathrm{H}_{2} \mathrm{O}=90: 10(\mathrm{v} / \mathrm{v})$ \\
KPS1 $=$ PAN $:$ PVPS $=75: 25(\mathrm{w} / \mathrm{w})$ & DMSO $: \mathrm{H}_{2} \mathrm{O}=90: 10(\mathrm{v} / \mathrm{v})$ \\
\hline
\end{tabular}

specific ratio. The KPV monolith was fabricated from a mixture of PAN and poly-4-vinylpyridine (PV4P) in a solvent mixture of DMSO and water. These experiments were repeated at least three times.

\subsubsection{Polyacrylonitrile (PAN): Poly-4-vinylpryidine (PV4P)}

Polymer composite KPV1 and two monoliths were prepared from PAN $(0.065 \mathrm{~g})$ and PV4P $(0.016 \mathrm{~g})$ in a similar manner as described for the PAN monoliths, using a 80:20 w/w of PAN and PV4P. Experiments were repeated at least three times.

\subsubsection{Polyacrylonitrile (PAN): Poly-4-vinylpyridine-co-styrene (PV4PPS)}

Polymer composite monoliths KPS1 and two from PAN and PV4PPS were prepared in a similar manner as described for the PAN monoliths, using a 80:20 w/w of PAN and PV4PPS. Experiments were repeated at least three times.

\subsubsection{Determination of Porosity of Polymer Monoliths}

In a typical experiment a small amount of granules of the sample were adhered to doubled sided tape and to a glass slide after which the excess sample was shaken off. The sample was then thoroughly coated using an Emscope SC500 gold coating machine. After obtaining sufficient coating on the sample, scanning electron microscope (SEM) analyses were performed by means of a Tuscan Vega3LMH SEM at $8 \mathrm{kV}$ and working distances ranging between $30 \mathrm{~mm}$ and $5 \mathrm{~mm}$ to determine the porosity of the polymer monolith. Typical micrographs are shown in Fig. 1.

\subsubsection{Determination of Pore Size Distribution of \\ Polymer Monoliths}

Nitrogen sorption measurements were performed by weighing of $0.081 \mathrm{~g}$ of monolith sample into a sample vial. The samples
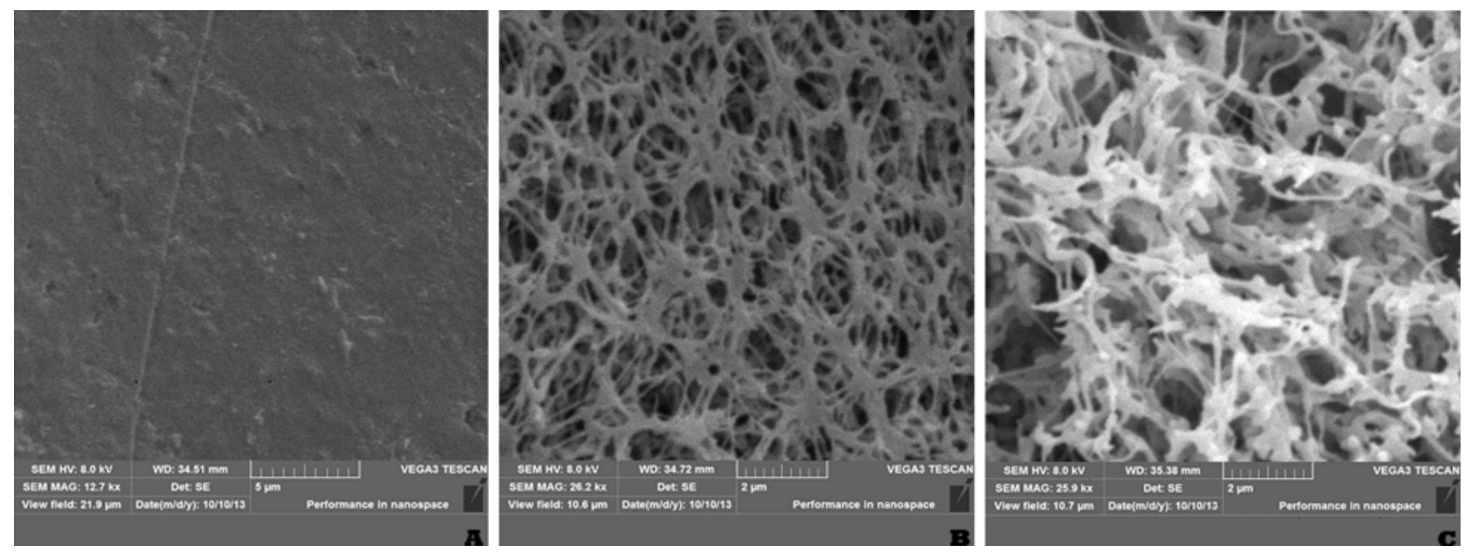

Figure 1 Intrinsic structure that resulted from a homogenous mixture of PAN and PVPS being rapidly cooled. The nascent outer layer is shown in A. This layer is non-porous and is formed by initial rapid change in temperature from high to low. $\mathbf{B}$ and $\mathbf{C}$ show the pores and structure that resulted as phase separation occurred. Some of this structure is monolithic. 
were degassed at $80{ }^{\circ} \mathrm{C}$ for $6 \mathrm{~h}$ and introduced into a cryogenic chamber and adsorption/desorption tests conducted at sub-zero temperatures on a Micromeritics Tristar 3000 sorption system. The surface areas were calculated by the Brunauer-EmmettTeller (BET) method, and the pore size distributions were obtained by the Barret-Joyner-Heled(BJH) method from the desorption branch of the isotherms. A typical pore size distribution is depicted in Fig. 2.

\subsubsection{Optimization of Metal Uptake by Polymer Monolith}

To achieve maximum uptake of metal ions, the sorption conditions, including concentration, volume, sorption time and $\mathrm{pH}$ were optimized. All optimization experiments were repeated at least three time.

\subsubsection{Influence of Metal Concentration in the Sample}

The optimization conditions used were kept constant for the five polymers (PAN2, PAN3, PAN4, KPV1 and KPS1) which were investigated to determine the optimum concentration of metal ion solution that would be required per $100 \mathrm{mg}$ of polymer sample. PAN1, which was the starting point based on the Uyama study ${ }^{6}$ proved to be difficult to reproduce consistently; hence PAN1 was not used in the sorption experiments. For each polymer material, $100 \mathrm{mg}$ was accurately weighed into poly-tops and four $10 \mathrm{~mL}$ solutions of $\mathrm{Cu}$ ions were prepared at 1, 3, 8 and $13 \mathrm{mg} \mathrm{L}^{-1}$ in each the four separate poly-tops containers in order to investigate the sorption at $\mathrm{mg} \mathrm{L}^{-1}$ range. The polymer and solution mixture was left to soak for $1 \mathrm{~h}$, after which the solution was quantitatively extracted and transferred into a $25 \mathrm{~mL}$ sample vial. The volume was filled to the mark using a $1 \% \mathrm{HNO}_{3}$ acid solution The above procedure was repeated to optimize for the $\mu \mathrm{g} \mathrm{L}^{-1}$ range using five solutions at 12, 25, 50, 100 and $200 \mu \mathrm{g} \mathrm{L}^{-1}$. Each experiment was repeated at least three times.

\subsubsection{Influence of Sample Volume}

The above achieved optimization conditions were kept constant for the five polymers which were being investigated in order to determine the optimum volume of metal ion solution that would be required to allow the maximum sorption per $100 \mathrm{mg}$ polymer material. $100 \mathrm{mg}$ of polymer materials were accurately weighed in triplicate for each of the five different types of polymers. For a $\mathrm{Cu}$ ion solution of a $200 \mu \mathrm{g} \mathrm{L} \mathrm{L}^{-1}$, three different volumes of 3, 5.5 and $10 \mathrm{~mL}$ were accurately measured and added to each polymer material. These polymer materials were allowed to soak for an hour after which they were quantitatively transferred into a $25 \mathrm{~mL}$ sample vial. The volume was subsequently filled to the mark using a $1 \% \mathrm{HNO}_{3}$ acid solution. The optimum volume was used in subsequent optimization.
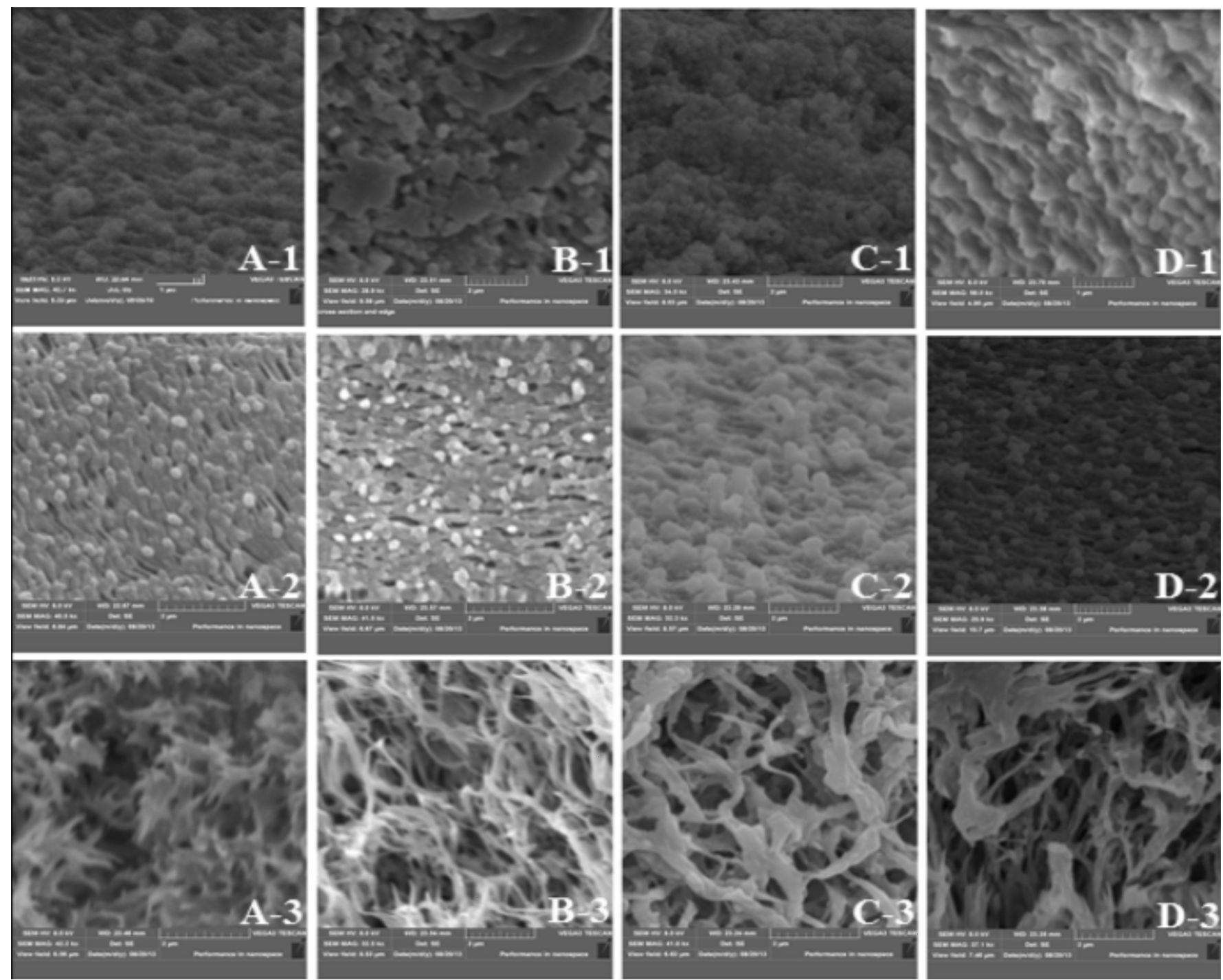

Figure 2 Change in morphology with the influence of heating period of the polymer; $\mathbf{A}$ ( 1 h heating intervals), B, C and D ( 15 min heating intervals). 


\subsubsection{Influence of Sorption Time}

The achieved optimization conditions were kept constant for the five polymer materials which were being investigated in order to determine the optimum time interval that was required for maximum sorption of metal ions by $100 \mathrm{mg}$ of polymer sample. Four $100 \mathrm{mg}$ polymer materials were accurately weighed for each of the five polymer samples prepared. Four aliquots of $5.5 \mathrm{~mL} \mathrm{Cu}(\mathrm{II})$ ion solution at a concentration of $200 \mu \mathrm{g} \mathrm{L}^{-1}$ were transferred into the weighed polymer samples. The aliquots were quantitatively transferred into $25 \mathrm{~mL}$ sample vials at periods of $1,3,4$ and $5 \mathrm{~h}$. The volume was subsequently filled to the mark using a $1 \% \mathrm{HNO}_{3}$ acid solution. The optimum sorption time was used for subsequent optimization.

\subsubsection{Influence of Sample $p H$}

The polymer materials prepared were investigated for possible use in the reclamation of mine wastewater hence $\mathrm{pH}$ optimization was carried out under acidic conditions ( $\mathrm{pH} 1-5)$ as the $\mathrm{pH}$ of mine waste is typically below 5 . To determine the optimum $\mathrm{pH}$ at which the polymer sample would remove the most metal ions in acidic conditions, the $\mathrm{pH}$ of a $\mathrm{Cu}$ ion solution of $200 \mu \mathrm{g} \mathrm{L}^{-1}$ was adjusted to 1, 2, 3, 4 and 5 with $\mathrm{NH}_{4} \mathrm{OH}$ in an $\mathrm{NH}_{4} /$ Acetate buffer. An amount of $100 \mathrm{mg}$ of polymer sample was accurately weighed and $5.5 \mathrm{~mL}$ aliquots of solution at the above mentioned $\mathrm{pH}$ values added. The polymer sample was left to soak for a period of $3 \mathrm{~h}$ after which the $\mathrm{Cu}$ ion solution was extracted and transferred quantitatively into a $25 \mathrm{~mL}$ sample vial. The volume was filled to the mark by $1 \% \mathrm{HNO}_{3}$ acid solution followed by analysis of the samples. These optimization experiments were repeated at least three times in each case.

\subsubsection{Optimized Sorption Study Procedure}

A $5.5 \mathrm{~mL}$ aliquot of the metal ion solution at a $\mathrm{pH} 4$ (adjusted by $\mathrm{NH}_{4}$ /Acetate buffer) was added to $100 \mathrm{mg}$ of polymer sample and left to soak for a period of $3 \mathrm{~h}$, the solution was quantitatively transferred into a $50 \mathrm{~mL}$ sample vial. The volume was filled to the mark using a $1 \% \mathrm{HNO}_{3}$ acid that was $\mathrm{pH}$ adjusted using the buffer solution. The spectroscopic method chosen for analysis in this case was GF-AAS owing to the low concentration ranges expected in the samples which were in the $\mu \mathrm{g} \mathrm{L}^{-1}$ range.

\subsubsection{Adsorption and Desorption Studies}

Metal adsorption and desorption experiments were carried out to determine if the monoliths used for initial uptake experiments could be recycled. It is important to note that only ternary solutions were investigated added to the monolith in the sequence $\mathrm{Cu}(\mathrm{II}), \mathrm{Ag}(\mathrm{I})$ and $\mathrm{Au}(\mathrm{III})$. Adsorption experiments were performed as described in section 2.3.6.5 with the metal ion dose kept at $200 \mu \mathrm{g} \mathrm{L}-1$ in five cycle. The polymer monoliths used in the adsorption experiment were preserved and used for the further adsorption/desorption experiments. The monoliths were rinsed with Milli- $Q$ water to remove physisorbed metal ions on the surface to avoid metal ions carry over from the previous experiment. The metal-loaded monoliths were then immersed in $\mathrm{HNO}_{3}$ at $\mathrm{pH} \sim 1$ and stirred at $100 \mathrm{rpm}$ for $3 \mathrm{~h}$ at ambient temperature. After filtration to recover the polymer, the monoliths were rinsed several times with Milli-Q water. The filtrate plus the rinsing water were made up to $50 \mathrm{~mL}$ with $1 \%$ $\mathrm{HNO}_{3}$ in a sample vial and analyzed for metal content. Five consecutive adsorption/desorption experiments were performed. The quantity of metal ions after each adsorption and desorption experiment was determined using GF-AAS and the efficiencies of desorption processes were calculated as follows: $\%$ of metal ion desorbed $=\left[\frac{Q_{\text {des }}}{Q_{\text {ads }}}\right] \times 100$ where $Q_{\text {des }}$ and $Q_{a d s}$ are quantities of metal ions in $\mu \mathrm{g} \mathrm{L^{-1 }}$ desorbed and adsorbed, respectively.

Experiments were run in triplicate $(n=3)$. Only KPS1, the polymer that demonstrated the best metal uptake under our given conditions was used to perform the adsorption/desorption experiments.

\subsection{Analysis of Samples}

Graphite furnace analyses were conducted using an Analitikjena ContrAA 700 at the recommended heating programme as set in the 'cookbook' since these conditions did not differ from those obtained after optimization for both pyrolysis and atomization. The analytes were quantified with relative ease and no apparent interferences were observed. The recoveries of the analytes fell within the acceptable range of $80-120 \%$. Calibrations were performed using working-ranges recommended by the instrument manufacturer. The standard concentrations ranged from $0-100 \mu \mathrm{g} \mathrm{L}^{-1}$ for each analyte.

\section{Results and Discussion}

\subsection{Fabrication of Macro- and Mesoporous Monoliths}

The monoliths were generally fabricated by dissolving either neat PAN or a mixture of PAN and PV4P or PV4PPS in a solvent mixture made up of DMSO or DMF and $\mathrm{H}_{2} \mathrm{O}$ or MeOH. The optimum $\mathrm{w} / \mathrm{w}$ composition of the polymers in any of the monoliths was established by varying the weight of the PAN in relation to the weight of the other polymer based on the porosity of the final composite material obtained (Fig. 1). In all composite materials, the optimum w/w mixture was found to be 80:20 (Table 1). Furthermore different solvent mixtures also affected the porosity of a monolith. Firstly by comparing DMSO to DMF as solvents that dissolved a polymer and using water as a non-solvent; monoliths prepared with DMSO had better porosity (Fig. S1). Also as a non-solvent, water produced monoliths with better porosity than methanol (Fig. S2). From SEM analyses the monoliths were generally found to be macro- or mesoporous with the majority of the pores lying in the macro-porous range. We also found that temperature and time of heating affected the porosity of all the monoliths, whether they were neat or composite materials. For example, a shorter heating period at constant temperature resulted in materials with better porosity; whilst increasing temperature even at the same heating time produced materials with poorer porosity (Figs. 1 and 2). The nascent outer layer is shown in (A) of Fig. 1. This layer is non-porous and is formed by the initial rapid change of temperature from high to low. (B) and (C) show the pores and structure that resulted as phase separation occurred. Some of this structure is monolithic and this can be explained to be a result of the diffusion gradient as the non-solvent displaces the solvent.

SEM images revealed that polymer samples formed an outer layer (skin), resulting from the sudden change of the environment upon quenching. The bulk of the sample showed an interconnected monolithic structure. Figure 1 shows a typical microstructure of these samples as observed under scanning electron microscopy (SEM). The intrinsic structure that resulted from a homogenous mixture of the polymers being rapidly cooled is depicted in the same figure. The nascent outer layer is shown in (A). This layer is non-porous and is formed by initial rapid change of temperature from high to low. (B) and (C) show the pores and structure that resulted as phase separation occurred. Some of this structure is monolithic and this can be explained to be a result of the diffusion gradient as the nonsolvent displaces the solvent. 
In summary, the best fabrication conditions for making the desired macro- and mesoporous monoliths were found to be: (i) solvent : non-solvent ratio of $90: 10 \mathrm{DMSO} / \mathrm{H}_{2} \mathrm{O}$ for either neat or composite material; (ii) temperature of $80^{\circ} \mathrm{C}$ and (iii) a maximum heating time of $6 \mathrm{~h}$.

\subsection{Quality and Quantitative Pore Size Determination}

Initial indications of whether any of the materials fabricated were porous or not was determined by its SEM micrographs. In experiments where the solvent, non-solvent pair used deviated too much from the $88: 12$ critical concentration recommended by Uyama, ${ }^{5}$ resulted in glassy non-porous materials (Figs. S3 and S4). This observation is possibly owing to remnants of the solvent that was used to dissolve a polymer not being completely removed when a large amount of a non-solvent is used to wash the monolith. To support this assertion we performed thermal analysis experiments of fabricated monoliths and they invariably contained DMSO (Figs. S5-S7).

Quantitative pore size distributions in all monoliths were determined by BET experiments. Typical BET data for the monolith are depicted in Figs. 3 and S8 and show that these monoliths are composed of mainly macro-pore sizes and only a small amount of meso-pores. The isotherms exhibit type III behaviour according to the IUPAC adsorption isotherms. ${ }^{13}$ These isotherms have a 'knee' around low relative pressure $(\mathrm{P} / \mathrm{Po})$ ranges, which is characteristic of materials with a low or no micropore volume.
This can be seen as the percentage incremental volume of the micropores in these samples which is close to zero and therefore negligible. These isotherms are depicted in Fig. S9.

The obtained average pore size and surface area of the prepared monoliths (PAN2, PAN3, PAN4, KPV1 and KPS1) as determined by BET analyses is approximately $15.89 \mathrm{~nm}$ with an average surface area of $18.79 \mathrm{~m} \mathrm{~g}^{-1}$. This surface area is considerably smaller than that obtained by the Uyama group for PAN monoliths who obtained an average surface area of $188 \mathrm{~m}^{2} \mathrm{~g}^{-1}$ and a pore volume of $0.71 \mathrm{~cm}^{3} \mathrm{~g}^{-1}$. Their reported experimental conditions were not identical to what we used in the fabrication of our polymers. ${ }^{6,14}$ This could be owing to the larger percentage of the pores lying in the macroporous range as opposed to the mesoporous range (see Figs. 3 and 4). This implies that the prepared polymer samples would not have a good metal ion removal capacity at high concentrations. This was observed in the optimization experiments where the removal capacity was less than $5 \%$ in the $\mathrm{mg} \mathrm{L}^{-1}$ concentration range but sorption was found to be maximized in concentration ranges between 25 and $200 \mu \mathrm{g} \mathrm{L}^{-1}$.

Interestingly, all monoliths except the composite materials from PAN and PV4PPS, show a Gaussian distribution of pore sizes around a specific pore size. For example PAN4 has its Gaussian distribution from 453.0-908.3 $\AA$ (Fig. 3 and Fig. S9). Another interesting observation to note is that KPS1, which showed a non-Gaussian pore size distribution (see Fig. S9)

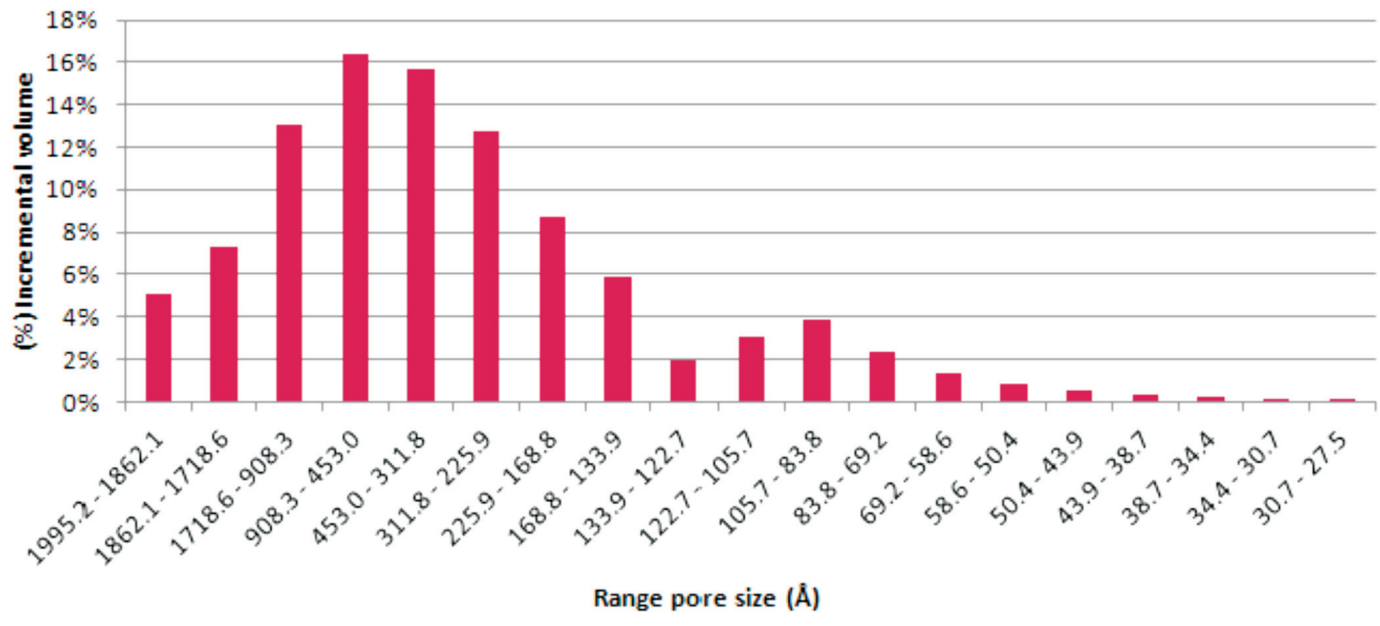

Figure 3 Pore size distributions in PAN1 polymer (majority of pores lie in the macroporous range).

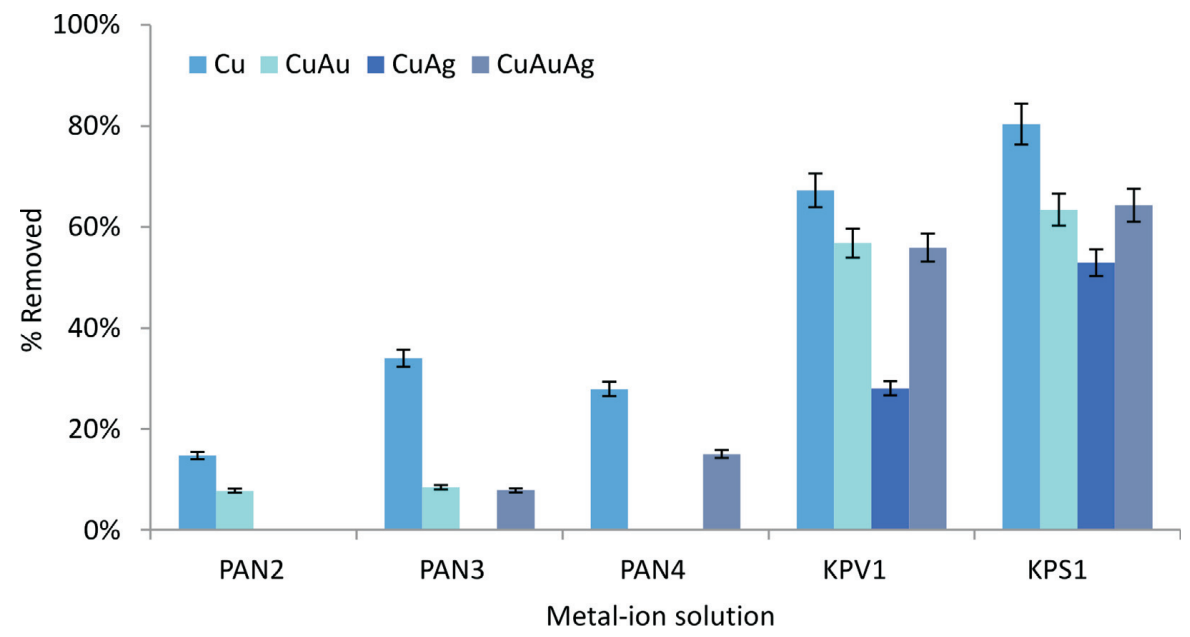

Figure 4 Sorption profile of $\mathrm{Cu}$ from single ion, binary $(\mathrm{Cu}-\mathrm{Au} \& \mathrm{Cu}-\mathrm{Ag})$ and ternary $(\mathrm{Ag}-\mathrm{Au}-\mathrm{Cu})$ solutions by polymer monoliths, monoliths, $\mathrm{n}=3$. The bars represent the standard error of the mean. 
showed the best metal ion uptake (vide infra). Here the majority of pore sizes are in the macro range between 417.5-2182.8 A. Hence, it is not surprising that this particular material performs the best in metal uptake experiments.

\subsection{Metal Sorption}

\subsubsection{Optimization Results of Metal Uptake by Polymer Materials using $\mathrm{Cu}$ as Model Metal Ion}

The working concentration of metal ions was determined for sorption studies using the prepared polymer samples. Preliminary sorption experiments were carried out in the concentration range of $1-10 \mathrm{mg} \mathrm{L}^{-1}$ as most reported studies using polymer sorbents indicate this as the working range. It was observed that the amount of metal ions adsorbed by the polymer increases steadily with increasing metal ion concentration but abruptly declines following a peak which implies saturation of binding sites on the polymer by the metal ions.

Sorption capacity of monolith was studied by varying the amount of sorbent material, contact time of sorbent with metal ions and $\mathrm{pH}$ of the aqueous mixture of the sorbent and metal ions. Typical results are shown in Figs. S10-S12 for $\mathrm{Cu}$ (II) ions which showed optimum sorbent concentration of $18 \mathrm{mg} \mathrm{L}^{-1}$ and contact time of $3 \mathrm{~h}$ at $\mathrm{pH} 4$ for $\mathrm{Cu}(\mathrm{II})$ ions.

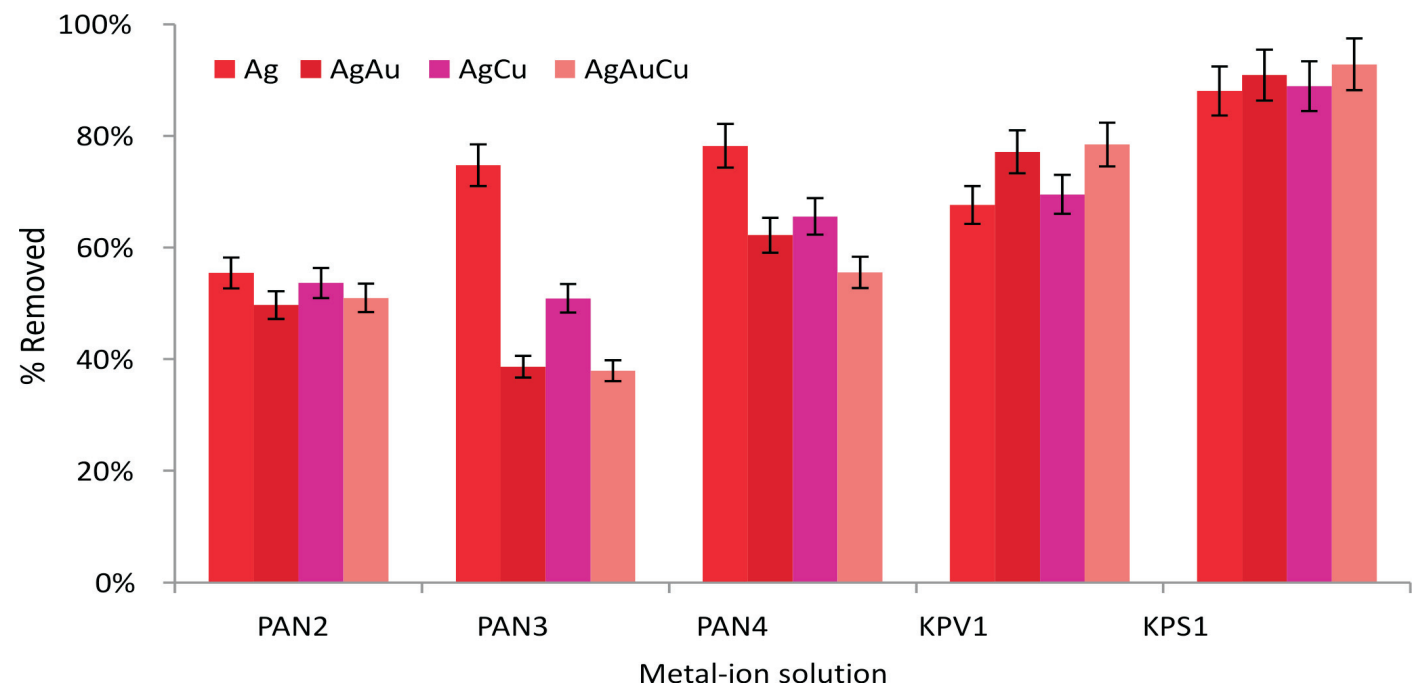

Figure 5 Sorption profile of Ag from single ion, binary (Ag-Au \&Ag-Cu) and ternary (Ag-Au-Cu) solutions by polymer monoliths, $\mathrm{n}=3$. The error bars represent the standard error of the mean.

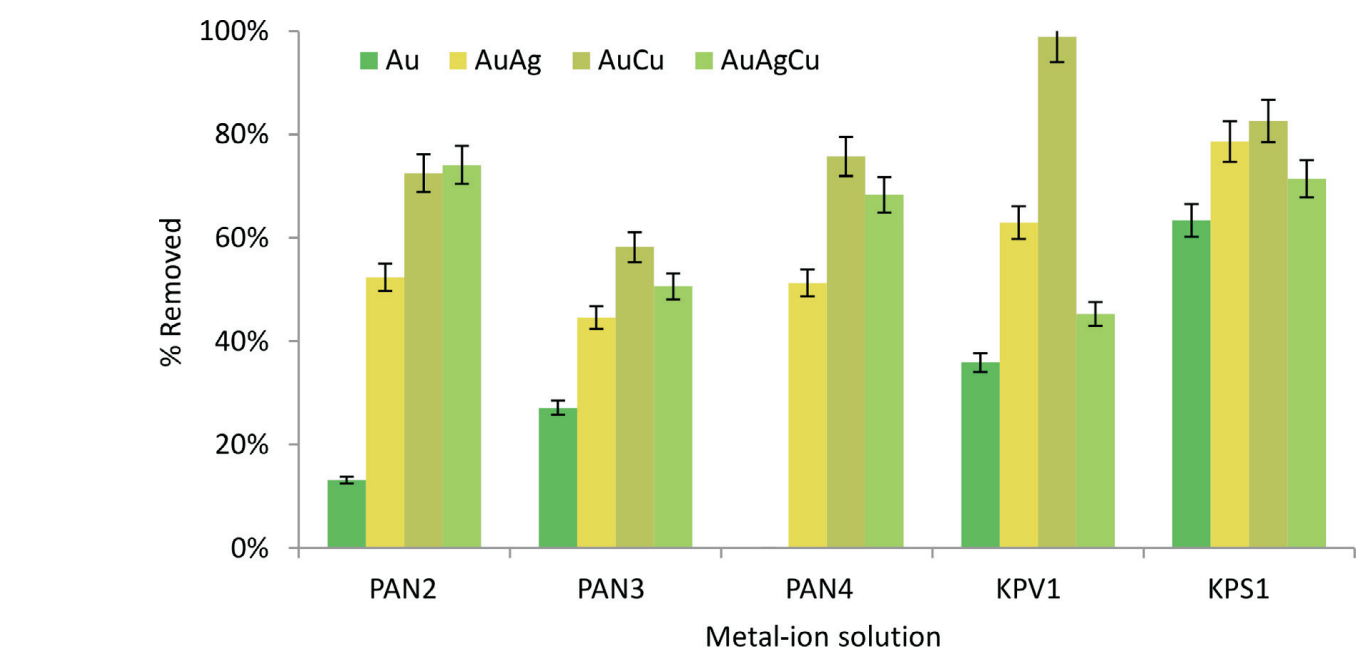

Figure 6 Sorption profile of $\mathrm{Au}$ from single, binary $(\mathrm{Au}-\mathrm{Ag} \& \mathrm{Au}-\mathrm{Cu})$ and ternary $(\mathrm{Au}-\mathrm{Ag}-\mathrm{Cu})$ solutions by polymer monoliths, $\mathrm{n}=3$. The error bars represent the standard error of the mean.

\subsubsection{Polymer Metal Uptake of Cu, Au and Ag in Single and Multi-components}

Sorption studies were performed using three Group 11 metals. These studies were carried out in single ion solutions as well as binary and ternary solutions in order to observe the sorption behaviour in a multi-ion solution.

The sorption results for the various metal ion solutions are illustrated in Figs. 4-6 and these show the sorption profile of the synthesized polymers as well as for KPS specifically for $\mathrm{Cu}(\mathrm{II})$, $\mathrm{Ag}(\mathrm{I}), \mathrm{Au}(\mathrm{III})$. Figure 4 illustrates the removal of $\mathrm{Cu}$ ions from solution. It is observed that in a single ion solution, sorption capacities reaching about $80 \%$ can be achieved dependent on the polymer sample used. When more ions are introduced into solution, it is observed that this sorption capacity declines to reach maximum at about $60 \%$. From Fig. 4 it is observed that the polymer sample with the highest sorption capacity is KPS1. The sorption of Ag as shown by Fig. 5 shows maximum sorption at around $80 \%$. It is further observed that the sorption of $\mathrm{Ag}$ in solution is not influenced by the presence of other metal-ions in solution but rather by the polymer sample used as observed by a narrower standard deviation across each polymer sample which ranged between $1 \%$ and $5 \%$. The Au sorption profile in Fig. 6 shows that $\mathrm{Au}$ reached an average sorption maximum of about $80 \%$. For all polymer samples, Au reaches peak sorption in 
binary solutions and a decline in sorption for ternary solutions possibly owing to increased competition for binding sites. The percentage relative standard deviations ranged between $1 \%$ and $5 \%$ in data represented in Figs. 4-7 but a larger range of 1-10\% was observed for some of the data in Figs. 8 and 9 but this is still within an acceptable range. The sequence in which the metal ions were added to the polymers affected the quantity of metal taken up.

\subsubsection{Competitive Uptake of Metal Ions by Polymer Monoliths} KPV and KPS

In order to determine how the metal ions were adsorbed by the polymer monoliths KPV and KPS, several experiments in which single, binary and ternary metal ions solutions were adsorbed were conducted. Figures 6-8 show the sorption of these metal ions by KPV and KPS.

KPS showed better removal of $\mathrm{Ag}$, where $90 \%$ of the initial

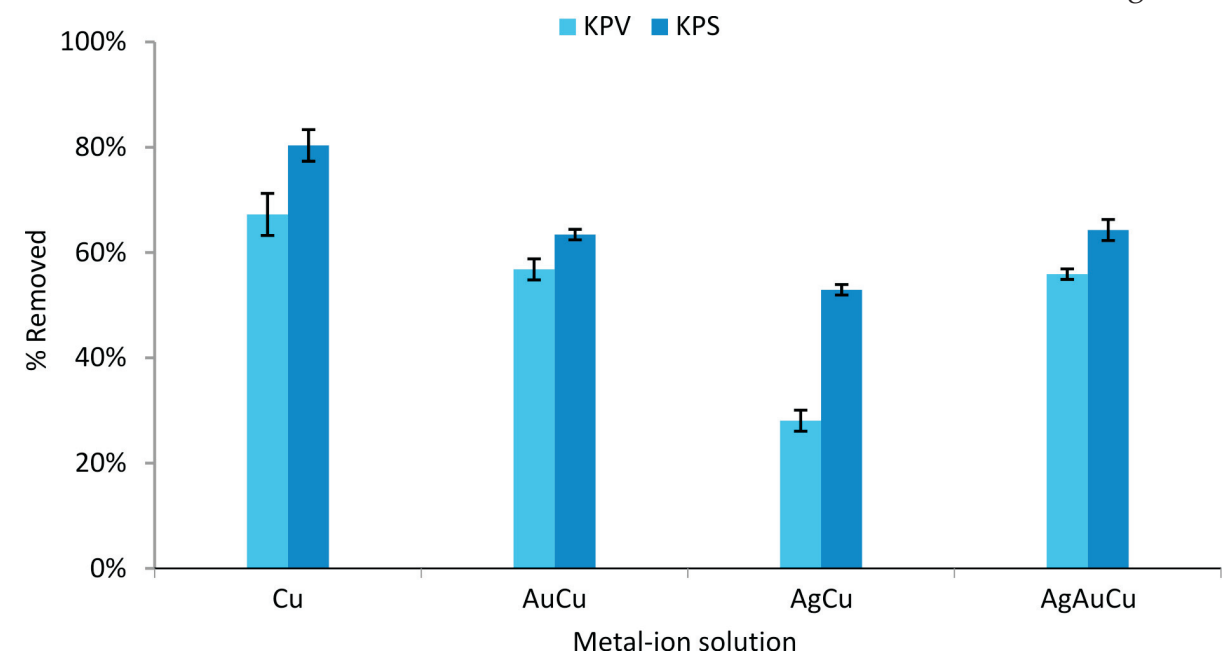

Figure 7 Removal of $\mathrm{Cu},(\mathrm{Cu}-\mathrm{Au} \& \mathrm{Cu}-\mathrm{Ag})$ and $(\mathrm{Au}-\mathrm{Cu}-\mathrm{Ag})$ solutions by monoliths KPV and KPS. KPS showed better metal removal than KPV, $\mathrm{n}=3$. The error bars represent the standard error of the mean.

\section{KPV $\quad$ KPS}

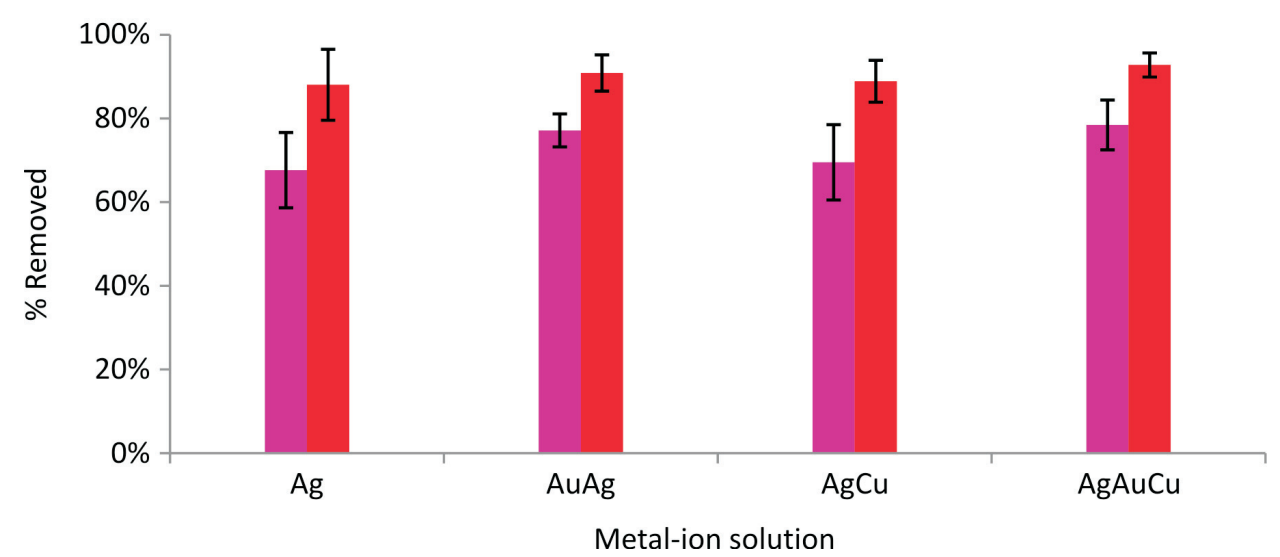

Figure 8 Removal of Ag, Ag-Au, Ag-Cu and Ag-Au-Cu solutions by KPV and KPS. $n$ = 3. The error bars represent the standard error of the mean.

$$
\square \mathrm{KPV} \square \mathrm{KPS}
$$

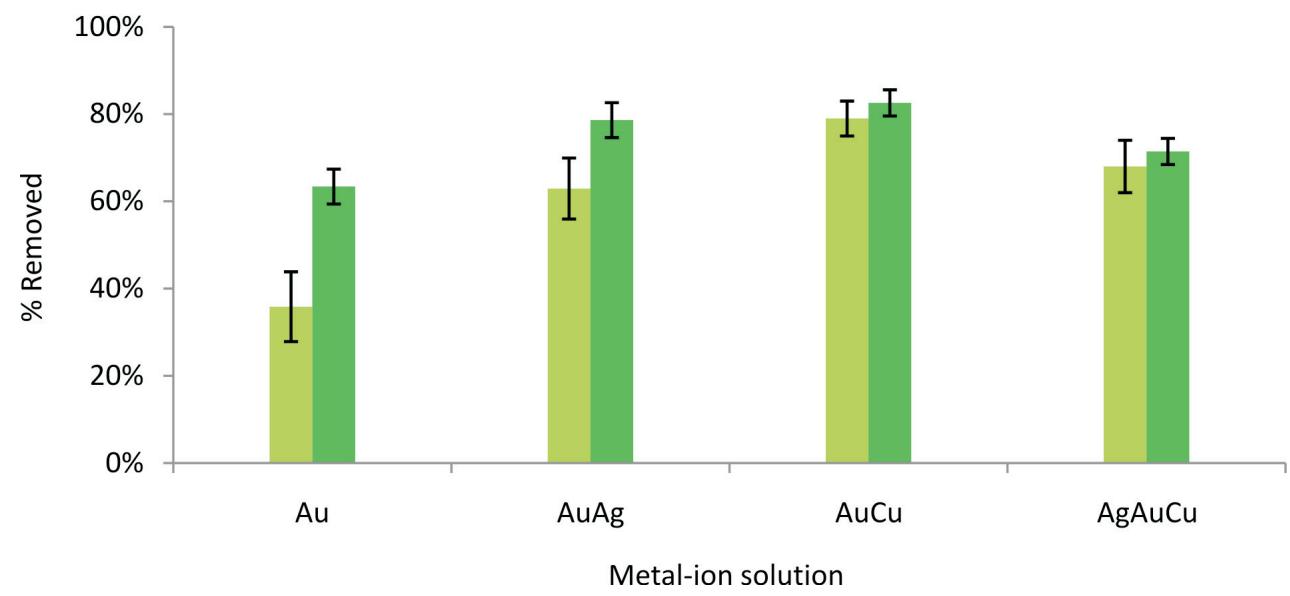

Figure 9 Removal of Au, Au-Ag, Au-Cu and Au-Ag-Cu solutions by KPV and KPS. $\mathrm{n}=3$. The error bars represent the standard error of the mean . 
concentration of Ag ions $\left(200 \mu \mathrm{g} \mathrm{L}^{-1}\right)$ was removed. The general trend observed for all polymers, including KPS, is $\mathrm{Cu}>\mathrm{Ag}>\mathrm{Au}$. These polymer samples could have a higher affinity towards these metal ions because of two possibilities. One would be the size of the sample polymer's pores would allow for better sorption of metals from solution through diffusion. It is evident from the pore size distribution (PSD) results that these samples have a large volume that is accounted for by macrovoids, which would allow for easier reach to the 3D microstructure for absorption. However, it has been reported that the sorption process was spontaneous for all metals ions in another study. ${ }^{15}$ This report states that the physisorption mechanism accounts for most of the metal ions interactions with the sorbent. ${ }^{11}$ In this case pyridine, styrene and nitrogen could allow for a more favourable interaction.

In support of this view that metals bind to sorbets is a study where PAN resins were aminated and used further to remove metals from solution. ${ }^{12}$ It was observed that certain bands that are characteristic for the resin shift following sorption experiments, which infers a metal bond that would have formed. The metal ions with the highest affinity for these KPS polymer samples are soft metals, which would preferentially react with softer ligands. The composition of the solution also influences the ability of these metal ions to bind or to be sorbed onto the polymer. In the presence of $\mathrm{Ag}$ and $\mathrm{Au}$, however, $\mathrm{Cu}$ is seen to be removed at a decreased rate. Ag removal for example will reach $90 \%$ whereas $\mathrm{Cu}$ will only be removed up to $65 \%$. This shows that these polymer samples react selectively to certain metal ions if they are present in solution. Another study noted that in the presence of other ions, the ability of the sorbent to remove metals from solution decreases. ${ }^{16}$ The same study explains that the reduction in sorption capacity of the same adsorbent in a metal solution composed of many metal ions compared to that composed of a single metal ion solution could be attributed to the lesser availability of binding sites. ${ }^{16}$ It is also rationalized that a metal with a higher affinity for a given binding site will be able to displace the weaker interacting metals. This would explain the differences observed in behaviour of $\mathrm{Cu}$ toward KPS samples in the presence of other metals.

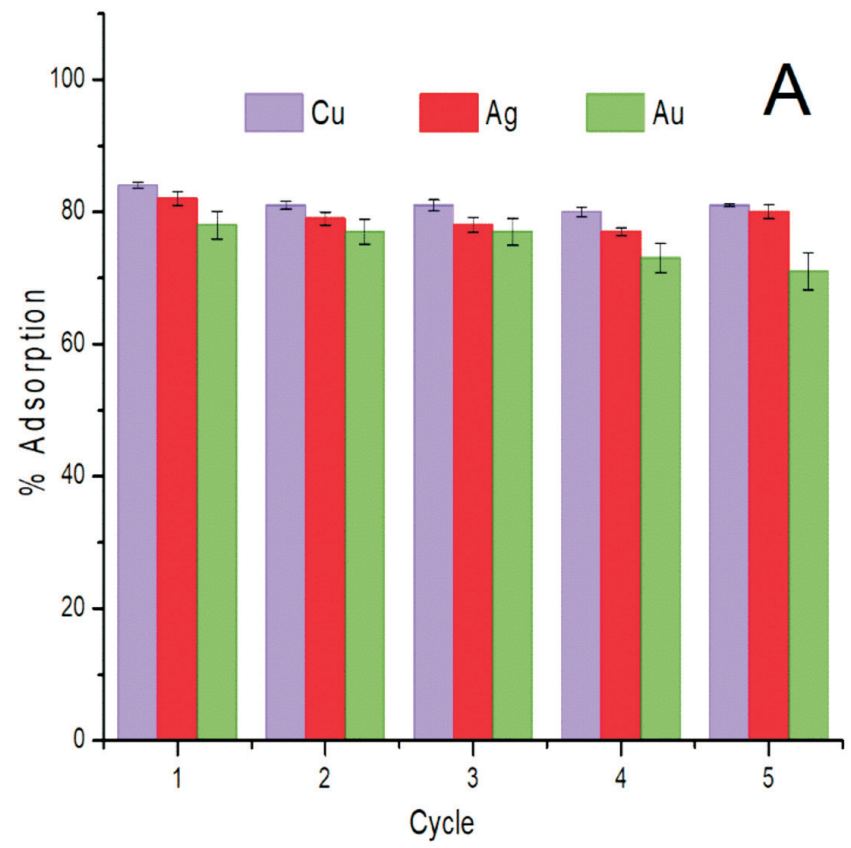

\subsubsection{Adsorption and Desorption Studies}

Determinations were conducted to establish if the polymer monolith (KPS1) that showed the best metal uptake could be recycled in adsorption/desorption experiments. This was performed using only ternary solutions as it is more likely that the three metal ions we tested would be present in acid mine drainage under similar conditions. Figure 10 shows the adsorption/desorption profiles of these metal ions by KPS1. The average adsorptions for $\mathrm{Cu}(\mathrm{II})$ was above $81 \%$, that for $\mathrm{Ag}(\mathrm{I})$ was slightly lower at $79 \%$ and $\mathrm{Au}(\mathrm{III})$ showing an above $75 \%$ average in the five cycles. The percentage adsorptions correlated perfectly with the size of the metal ions where the smallest ion showed the highest binding capacity and the largest metal ion the least. The differences in the binding capacities are relatively small, again correlating perfectly with the small differences in the metallic ion sizes. This could be because the adsorption affinities (binding energies) of the polymer and metal ion followed that order. The general trend observed for binding of the metal ions is $\mathrm{Cu}>\mathrm{Ag}>\mathrm{Au}$. An opposite trend $(\mathrm{Cu}<\mathrm{Ag}<\mathrm{Au})$ was observed for the desorption experiments with approximately $95 \%$ of $\mathrm{Au}(\mathrm{III})$ desorbing with the greatest ease followed by $\mathrm{Ag}(\mathrm{I})$ at $90 \%$ and then $\mathrm{Cu}(\mathrm{II})$ at $87 \%$. This trend also makes sense in that it would be expected that the metal ion with the lowest binding affinity would desorb with the greatest ease from the polymer.

The slightly higher adsorption rates in these experiments compared to the results obtained in section 3.3 .3 could be attributed to fact that the monoliths in the present case were more finely ground, increasing the surface area. An increase in surface area would have exposed more binding sites from the polymer monolith.

\section{Conclusion}

Three types of polymer monoliths were prepared in this study; one type that has only PAN, the second a mixture of PAN and PV4P (KPV) and the third a mixture of PAN and PV4PPS (KPS). Of the three monoliths, KPS showed the highest capacity to adsorb Group 11 metal ions. This is likely due to two the nitrogen donor sites in KPS as well as the spacing provided by the pendant phenyl groups in the styrene component of KPS. Secondly,

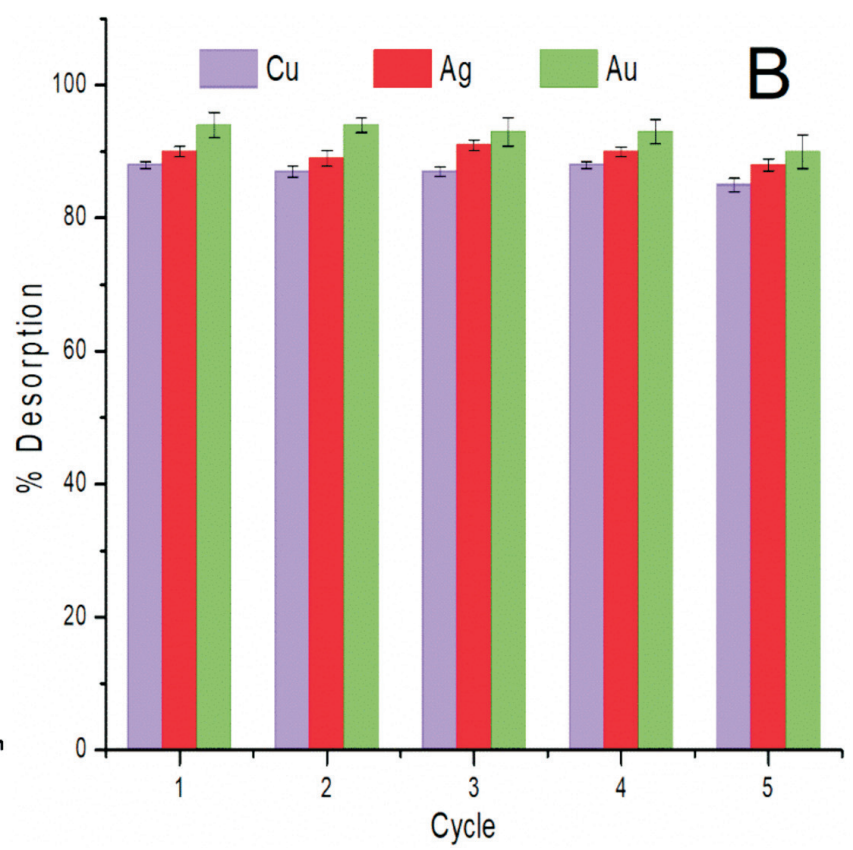

Figure 10 Adsorption (A) and desorption (B) profiles of ternary solutions of Cu-Ag-Au by KPS1 $\mathrm{n}=3$. The error bars represent the standard error of the mean. 
the polymer monoliths adsorbed at lower concentration and became saturated at concentrations higher than $8 \mathrm{mg} \mathrm{L}^{-1}$. The monoliths are therefore considered as ideal adsorbent for the removal of trace metals; and that we are currently investigating their ability to clean wastewater with municipal water samples in the Mpumalanga province in South Africa.

\section{Acknowledgements}

We acknowledge the National Research Foundation and the University of Johannesburg for financial support of this project.

\section{${ }^{8}$ ORCID iDs}

O. Zinyemba: orcid.org/0000-0003-3457-1832

\section{References}

1 S. Khan, Q. Cao, Y.M. Zheng, Y.Z. Huang and Y.G. Zhu, Health risks of heavy metals in contaminated soils and food crops irrigated with wastewater in Beijing, China. Environ. Pollution, 2008, 152, 686-692.

2 M.T. Gokmen and F.E. Du Prez, Porous polymer particles - A comprehensive guide to synthesis, characterization, functionalization and applications. Prog. Polym. Sci., 2012, 37, 365-405.

3 (a) T.B. Tennikova, F. Svec and B.G. Belenkii, High-performance membrane chromatography. A novel method of protein separation J. Liquid Chromatogr., 1990, 13, 63-70. (b) T.B. Tennikova, M. Bleha, F. Svec, T.V. Almazova and B.G. Belenkii, High-performance membrane chromatography. A novel method of protein separation, J. Chromatogr., 1991, 555, 97-107.

4 Y. Xin, T. Fujimoto and H. Uyama, Facile fabrication of polycarbonate monolith by non-solvent induced phase separation method, Polymer, 2012, 53, 2847-2853.

5 K. Okada, M. Nandi, J. Maruyama, T. Oka, T. Tsujimoto, K. Kondohand and H. Uyama, Fabrication of mesoporous polymer monolith: a template-free approach, Chem. Commun., 2011, 47, 7422-7424.
6 K. Okada, T. Oka, T. Tsujimoto and H. Uyama, Polyacrylonitrile porous body, American Patent publication, 2013, US 2013/0058858 A1.

7 R. Dong, J. Zhao, Y. Zhang and D. Pan, Morphology control of polyacrylonitrile (PAN) fibers by phase separation technique, J. Polym. Sci., Part B: Polym. Phys., 2009, 47, 261-275.

8 L. Tan, S. Lui and D. Pan, Water effect on the gelation behavior of polyacrylonitrile/dimethyl sulfoxide solution, Colloids and Surfaces A: Physicochem. Eng. Aspects, 2009, 340, 168-173.

9 P.Kotze \& J.H.J. van Veren, Bioaccumulation of copper and zinc in Oreochromis mossambicus and Clarias gariepinus, from the Olifants River, Mpumalanga, South Africa, Water SA, 1999, 25, 99.

10 G.M. Chieng, E.S. Seanego and O.I. Nkwonta, Impacts of mining on water resources in South Africa: a review. Sci. Res. Essays, 2010, 5 3351-3357.

11 K. Naicker, E. Cukrowska, T.S. McCarthy, Acid mine drainage from gold mining activities in Johannesburg, South Africa and environs. Environ. Pollut., 122: 29-40.

12 E.M.M. Wanda, B.B. Mamba and T.A.M. Msagati, Determination of the water quality index ratings of water in the Mpumalanga and North West provinces, South Africa. Phys. Chem. Earth 92, 2016, 70-78.

13 K.S.W. Sing, D.H. Everett, R.A.W. Haul, L. Moscou, R.A. Pierotti, J. Rouquerol and T. Siemieniewska, Reporting physisorption data for gas/solid systems with special reference to the determination of surface area and porosity, Pure E Appl. Chem., 1985, 57, 603-619.

14 Y. Shu, J. Maruyama, S. Satoshi, S. Maruyama, Y. Shen, and H. Uyama, Fabrication of N-doped and shape-controlled porous monolithic carbons from polyacrylonitrile for supercapacitors, RSC Adv., $2017,7,43172$.

15 G.R. Kiani H. Sheikhloie and N. Arsalani, Heavy metal ion removal from aqueous solutions by functionalized polyacrylonitrile, Desalination, 2011, 269, 266-270.

16 J. Rouquerolt, D. Avnir, C.W. Fairbridge, D.H. Everett, J.H. Haynes, N. Pernicone, J.D.F. Ramsay, K.S.W. Sing, and K.K. Unger, Recommendations for the characterization of porous solids, Pure Appl. Chem.,1994, 66, 1739-1758. 


\section{Supplementary material to:}

K. Mphanje, O. Zinyemba and J. Darkwa,

Fabrication of Nitrogen Donor Macro- and Meso-porous Materials for Group 11 Metal Ions Sorption

S. Afr. J. Chem., 2018, 71, 94-102. 


\section{Supplementary material}

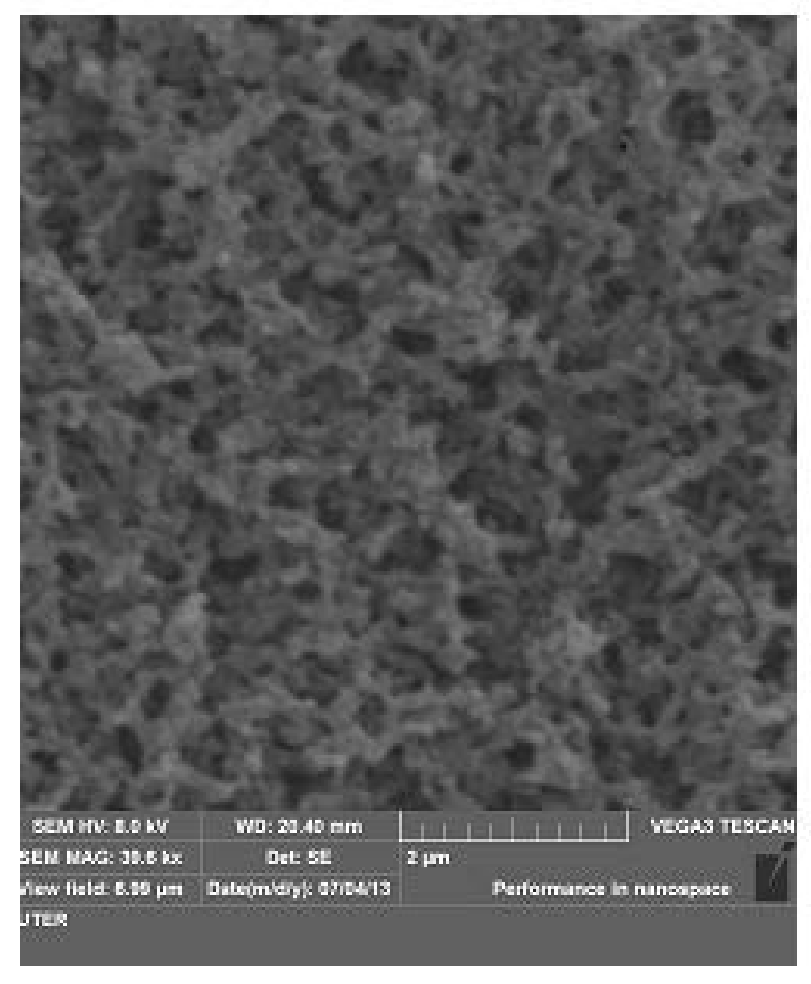

DMF-H2O 85:15

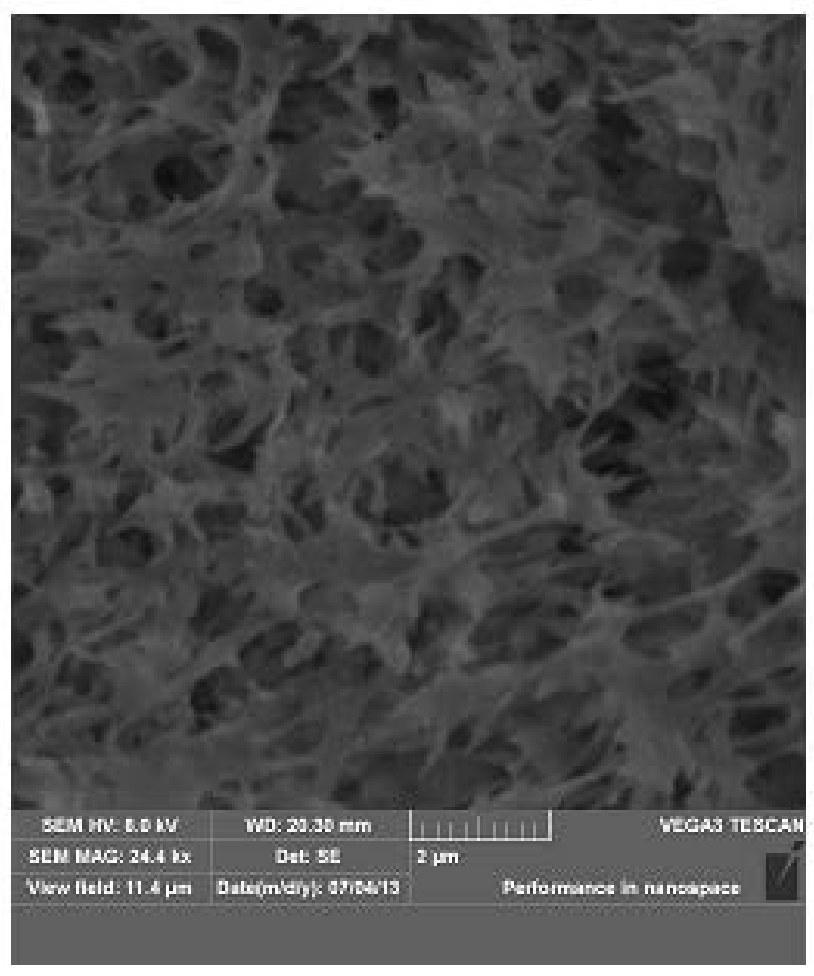

DMSO-H2O 85:15

Figure S1: The effects of different solvents used for dissolution of the polymers on the microstructure of the formed porous samples. 

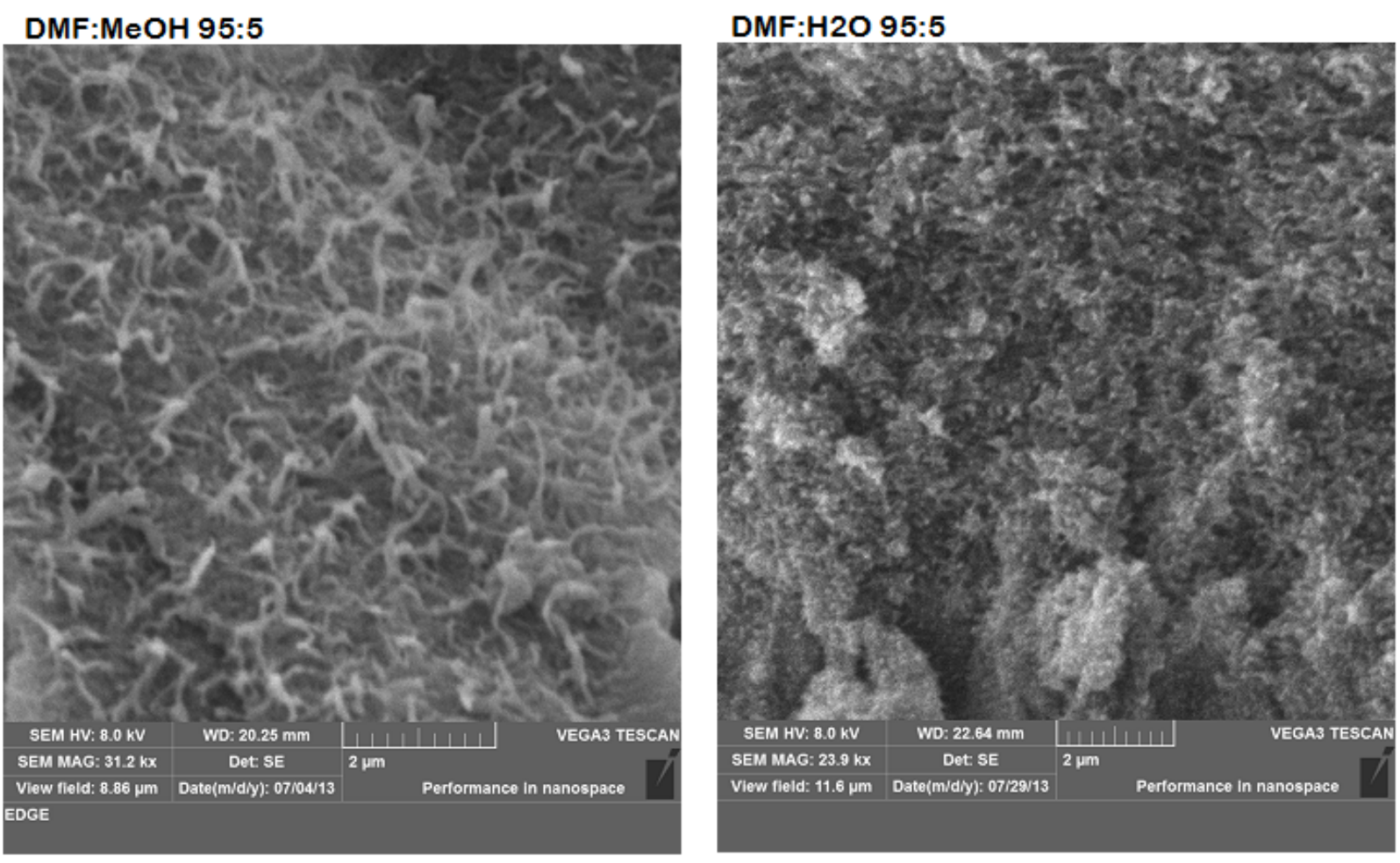

Figure S2: Samples prepared using different non-solvents, it can be seen that most polymer samples prepared using DMF:MeOH S/NS pair yield glassy/combination products whereas when water is used almost exclusively porous samples result. 


\section{DMSO-H2O 90:10}
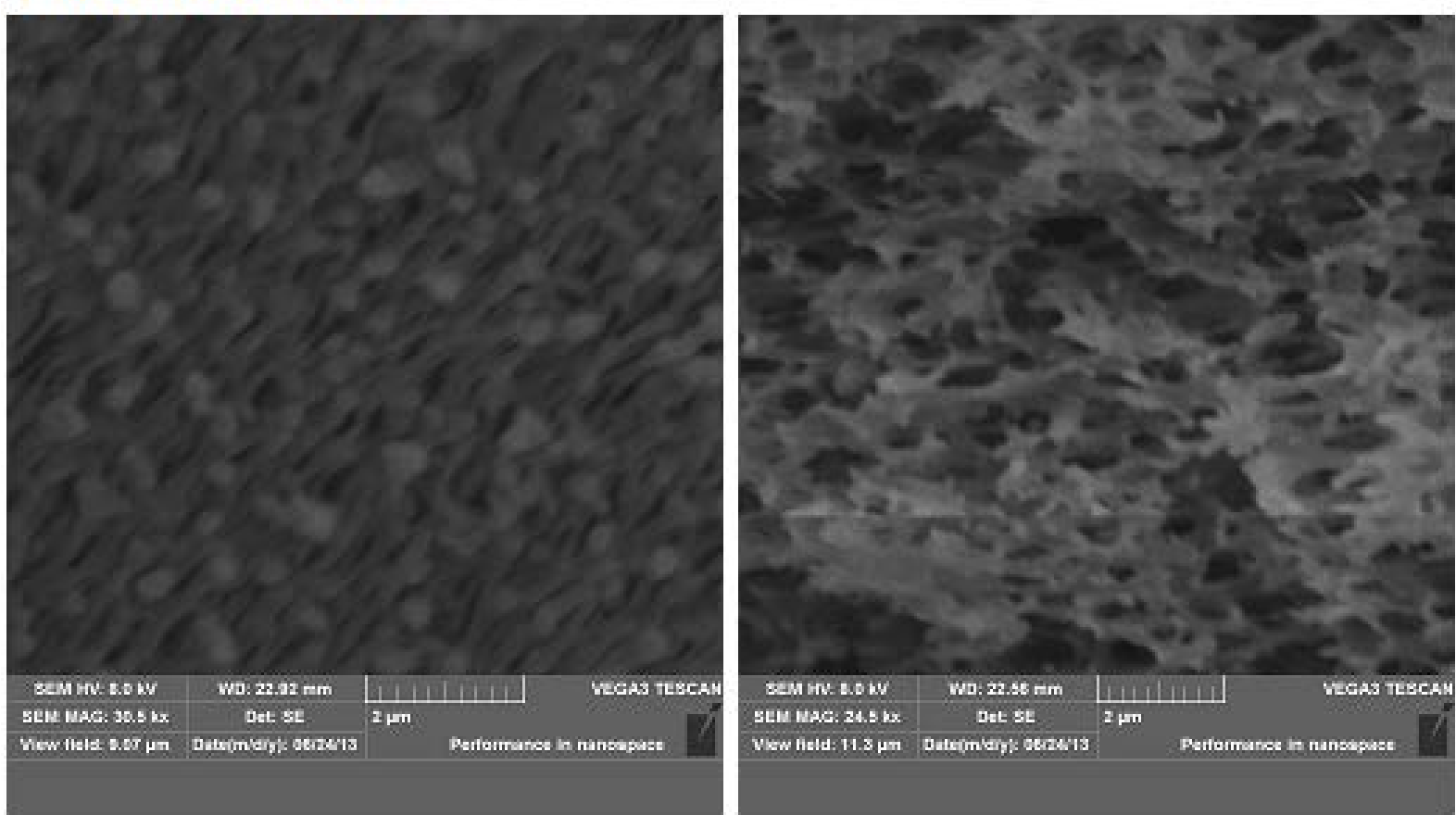

\section{DMSO-MeOH 90:10}
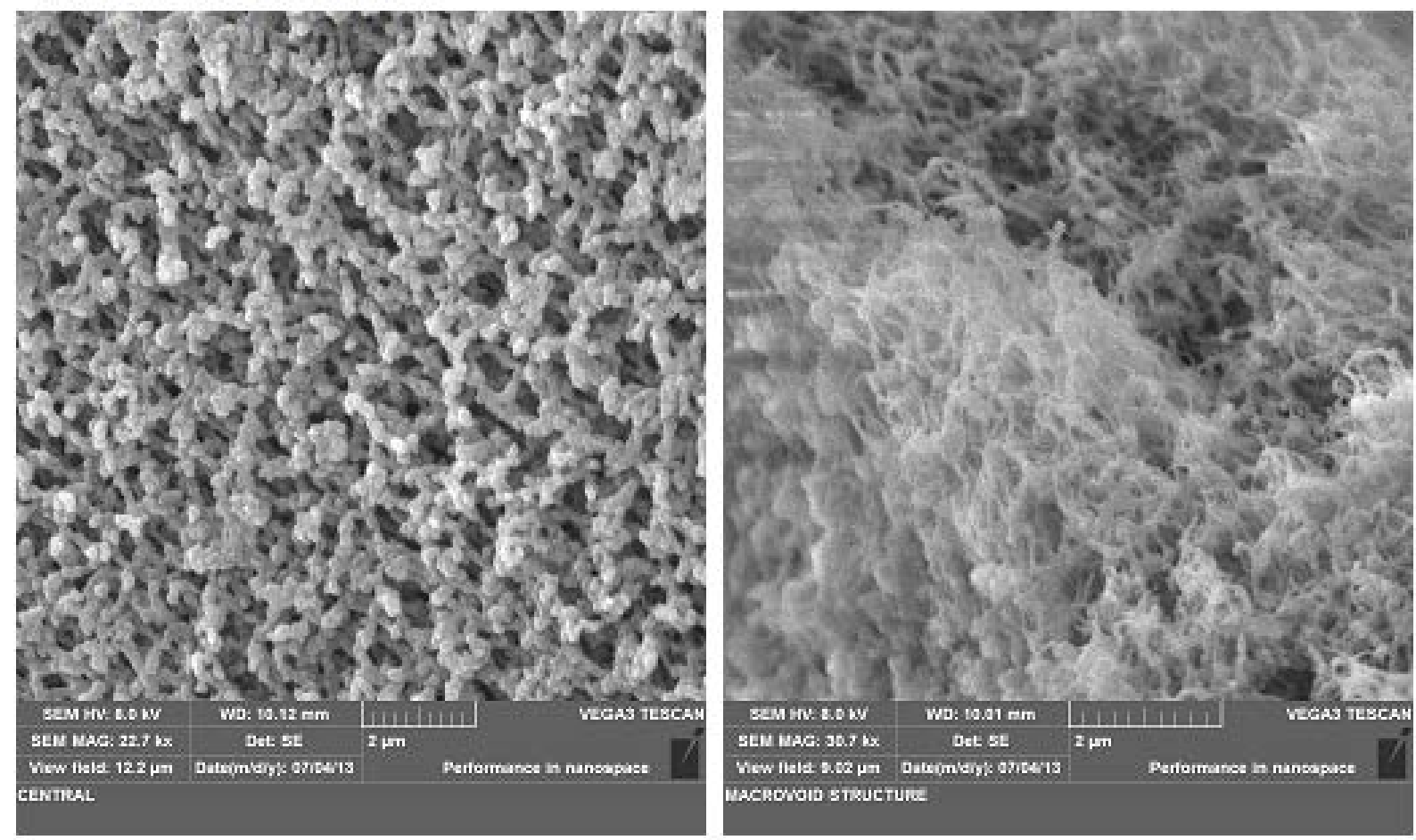

Figure S3: Samples prepared using DMSO as solvent show better flexibility in using different non-solvent pairs, in both cases as shown in the graphic the sample results in porous samples with varied microstructures dependant on experiment conditions and the non-solvent. 


\section{DMSO:H2O 85:15}

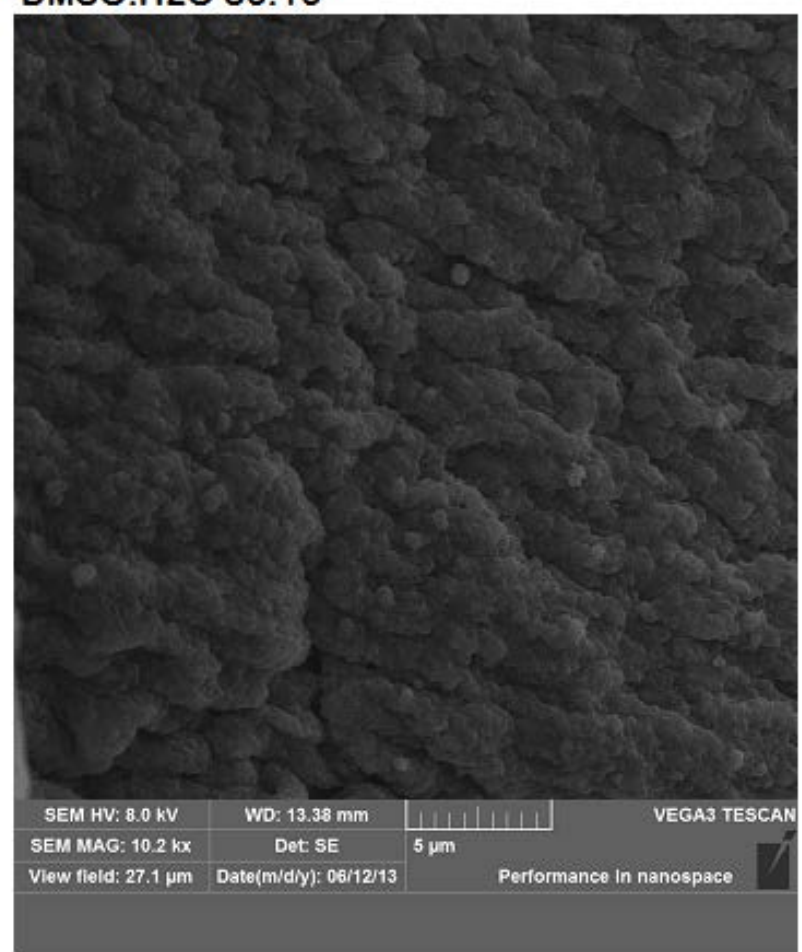

\section{DMSO:H2O 88:12}

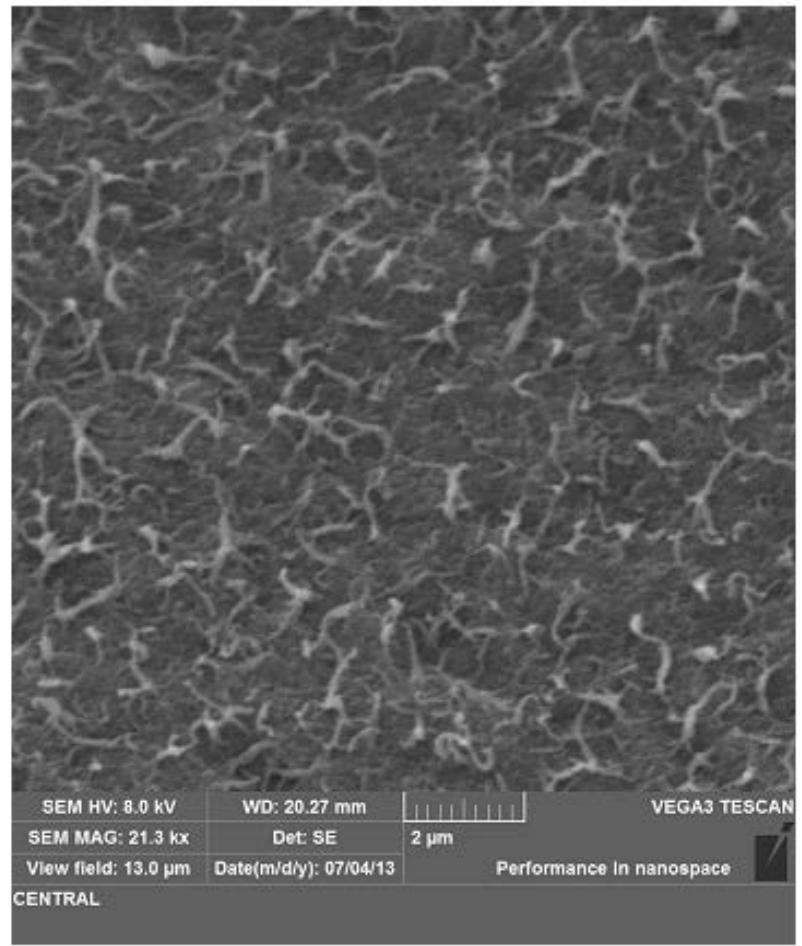

DMF:MeOH 95:5

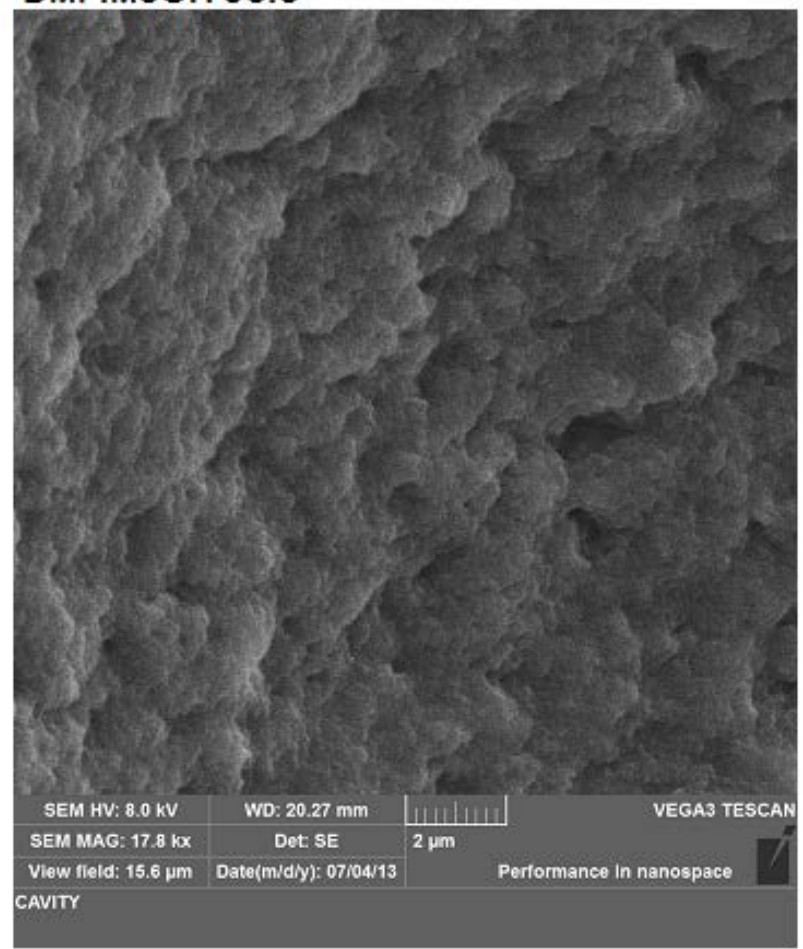

DMSO:H2O 85:15

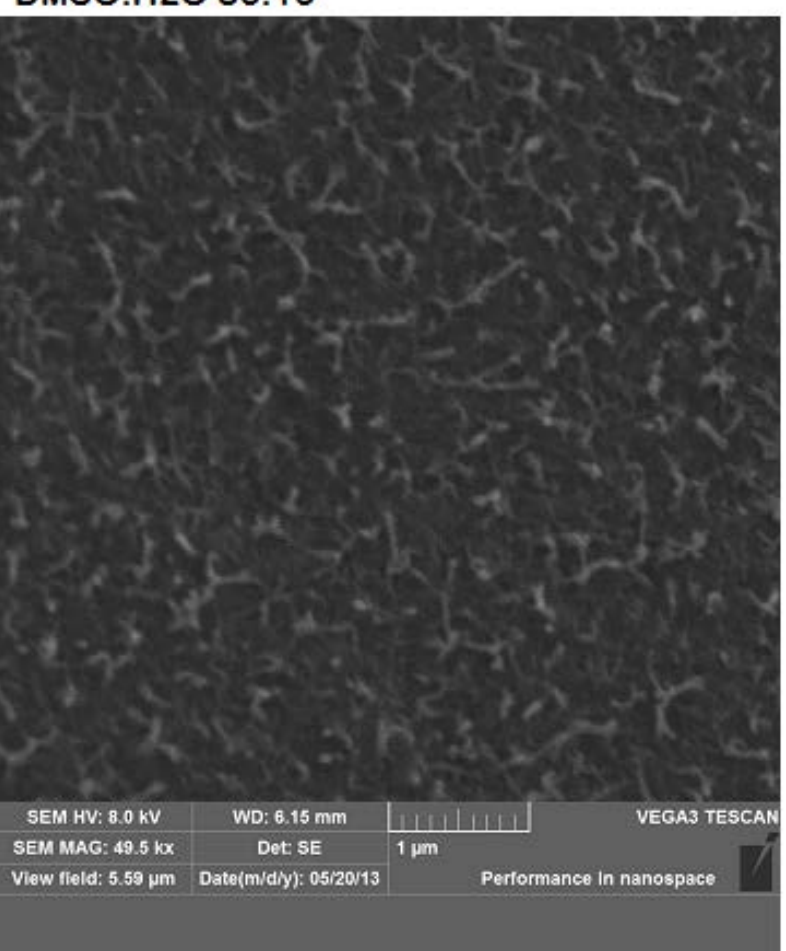

Figure S4: Glassy samples resulting from non-solvent induced phase separation and thermally induced phase separation respectively. 


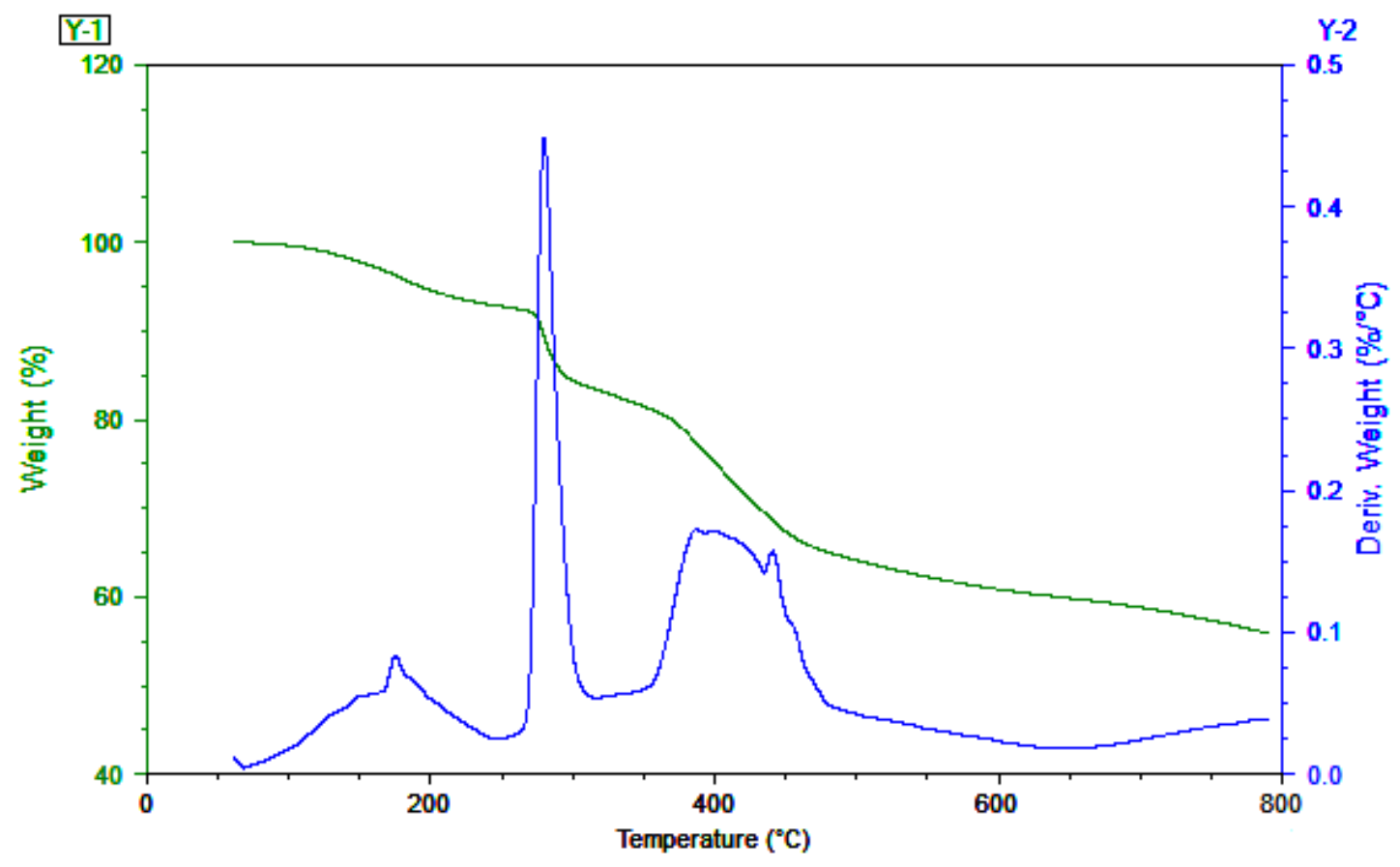

Figure S5: TGA and DTG thermograms of glassy PAN samples produced, the mass loss around $200^{\circ} \mathrm{C}$ can be associated with that of the solvent used (in this case DMSO). 


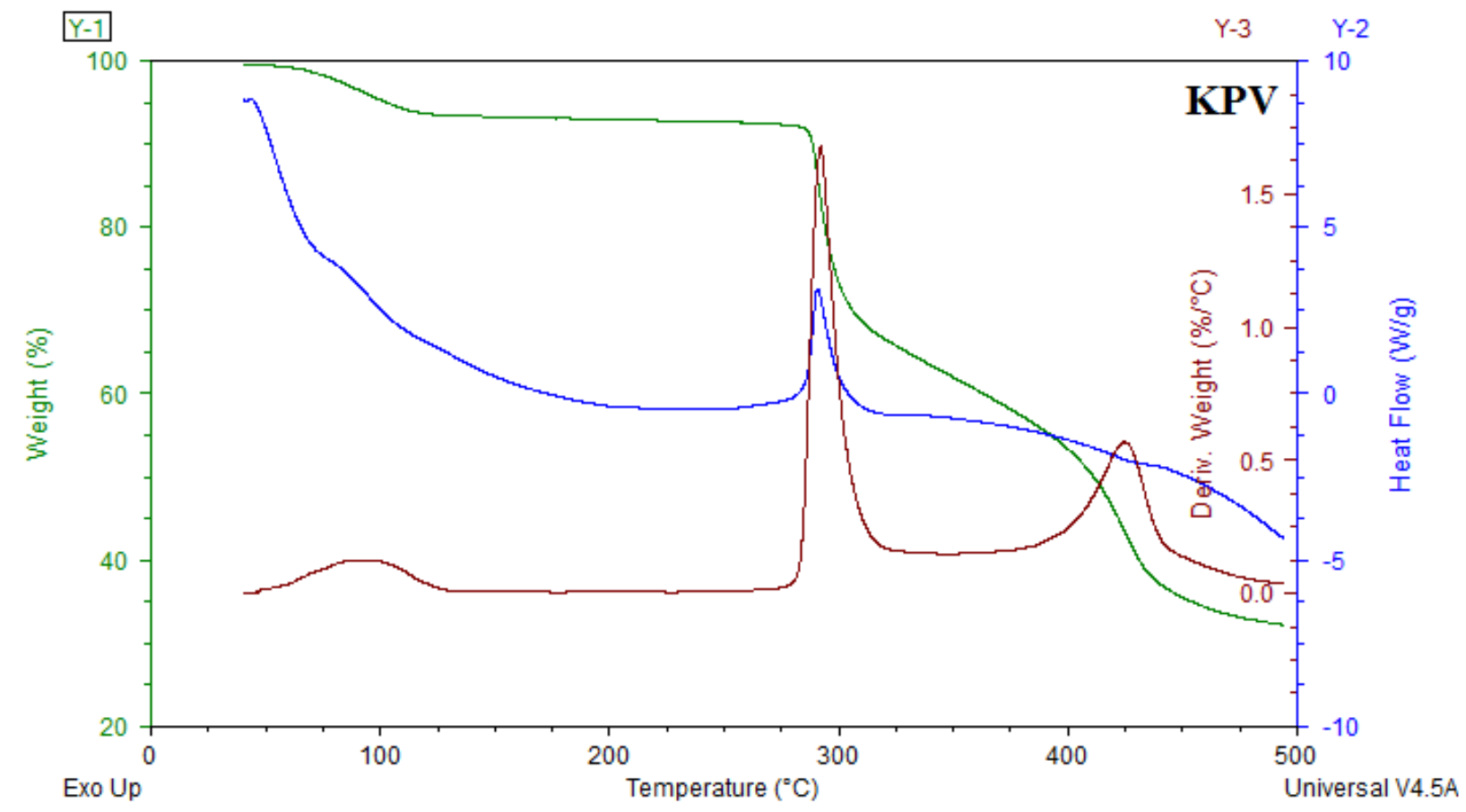

Figure S6: Typical thermal profile obtained from KPV samples. The green curve denotes the TGA curve, the blue curve denotes the DTG used to observe more clearly the TGA transformation and the red curve denotes the relevant DSC curve. 


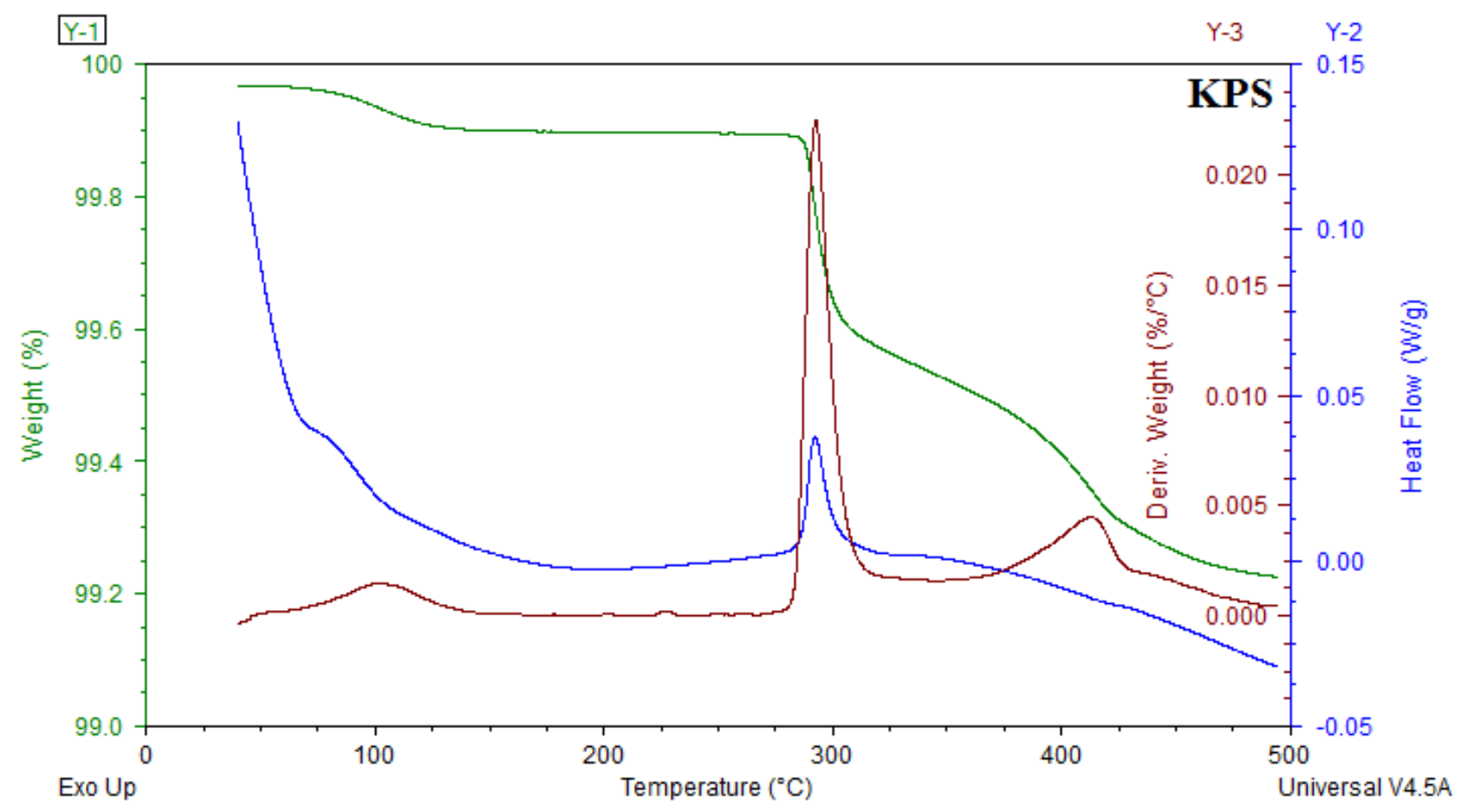

Figure S7: Typical thermal profile obtained from KPS samples. The green curve denotes the TGA curve, the blue curve denotes the DTG used to observe more clearly the TGA transformation and the red curve denotes the relevant DSC curve. 

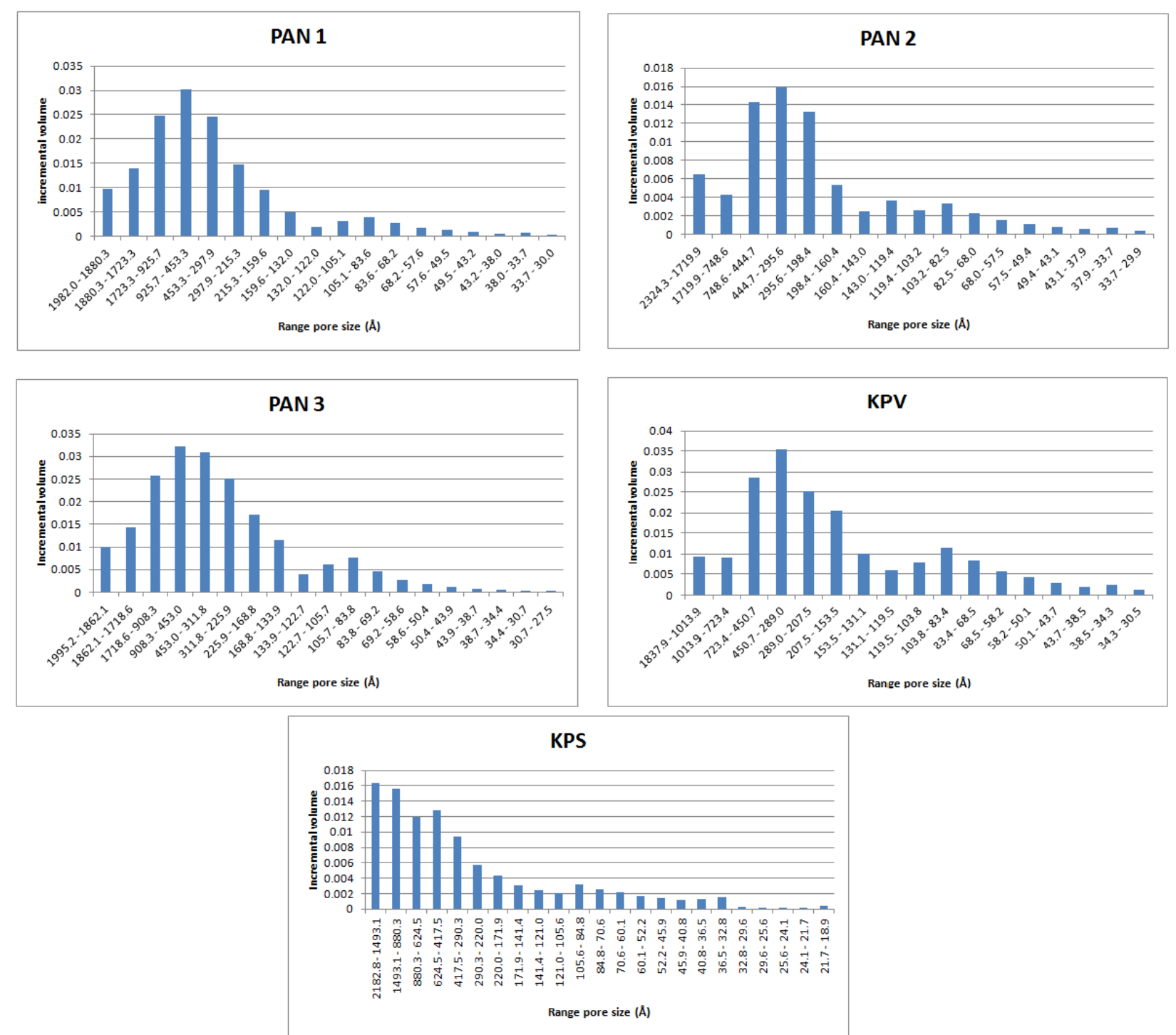

Figure S8: Pore size distribution trend of the five polymer samples used for sorption studies. 

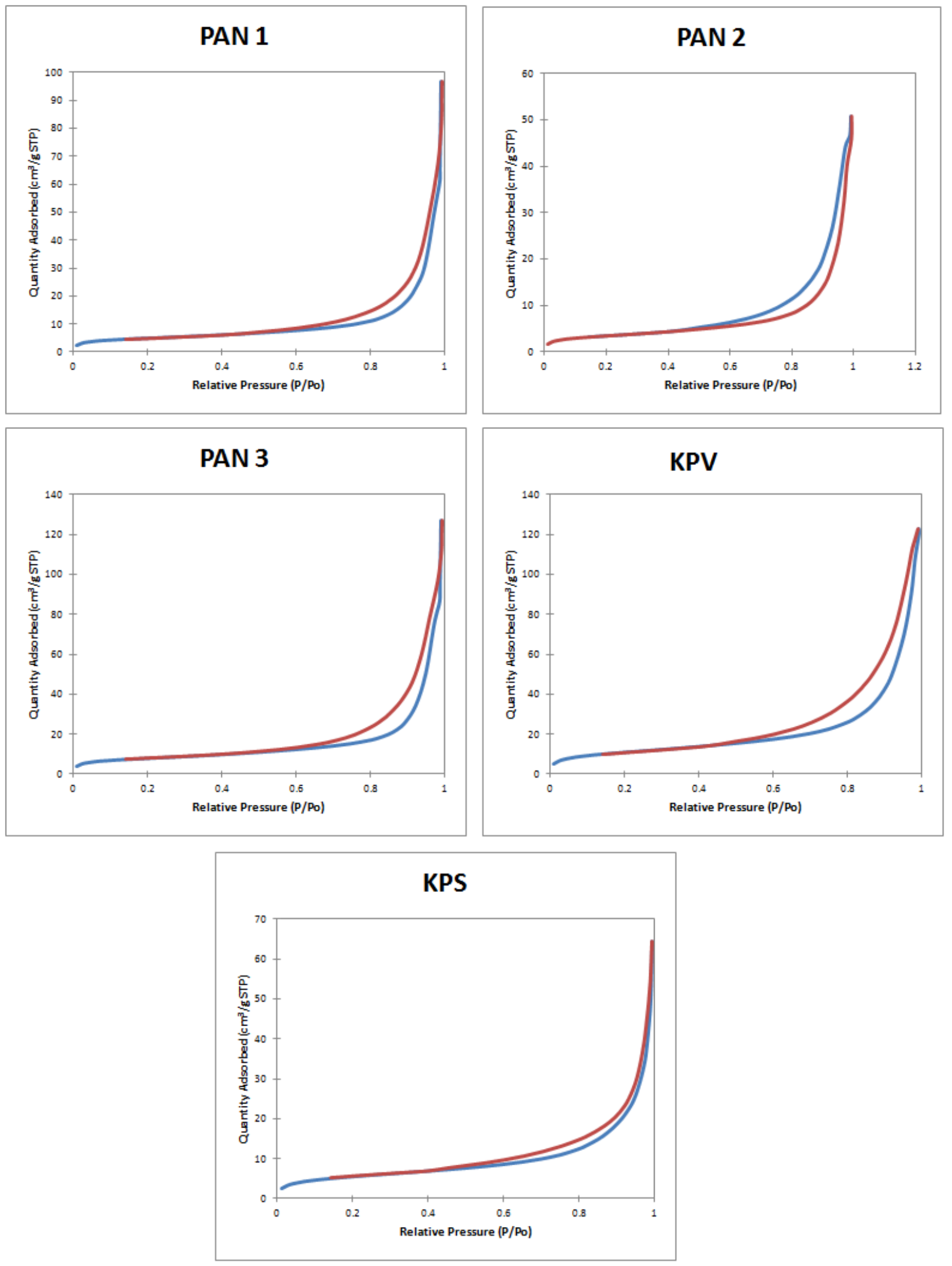

Figure S9: Isotherms associated with the prepared polymer samples used for metal sorption. 


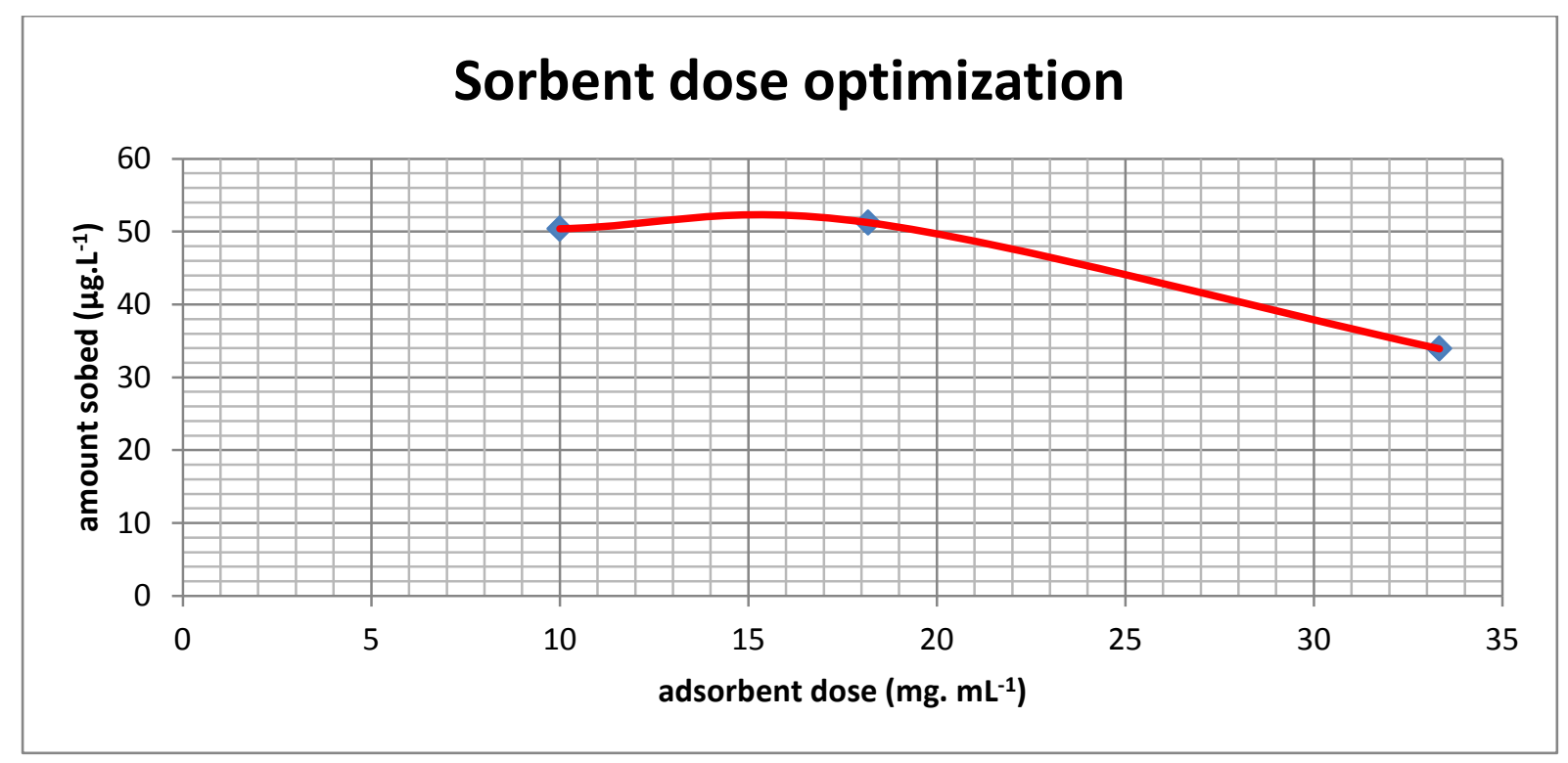

Figure S10: The effect of varying amount of $\mathrm{Cu}(\mathrm{II})$ ions and sorbent.

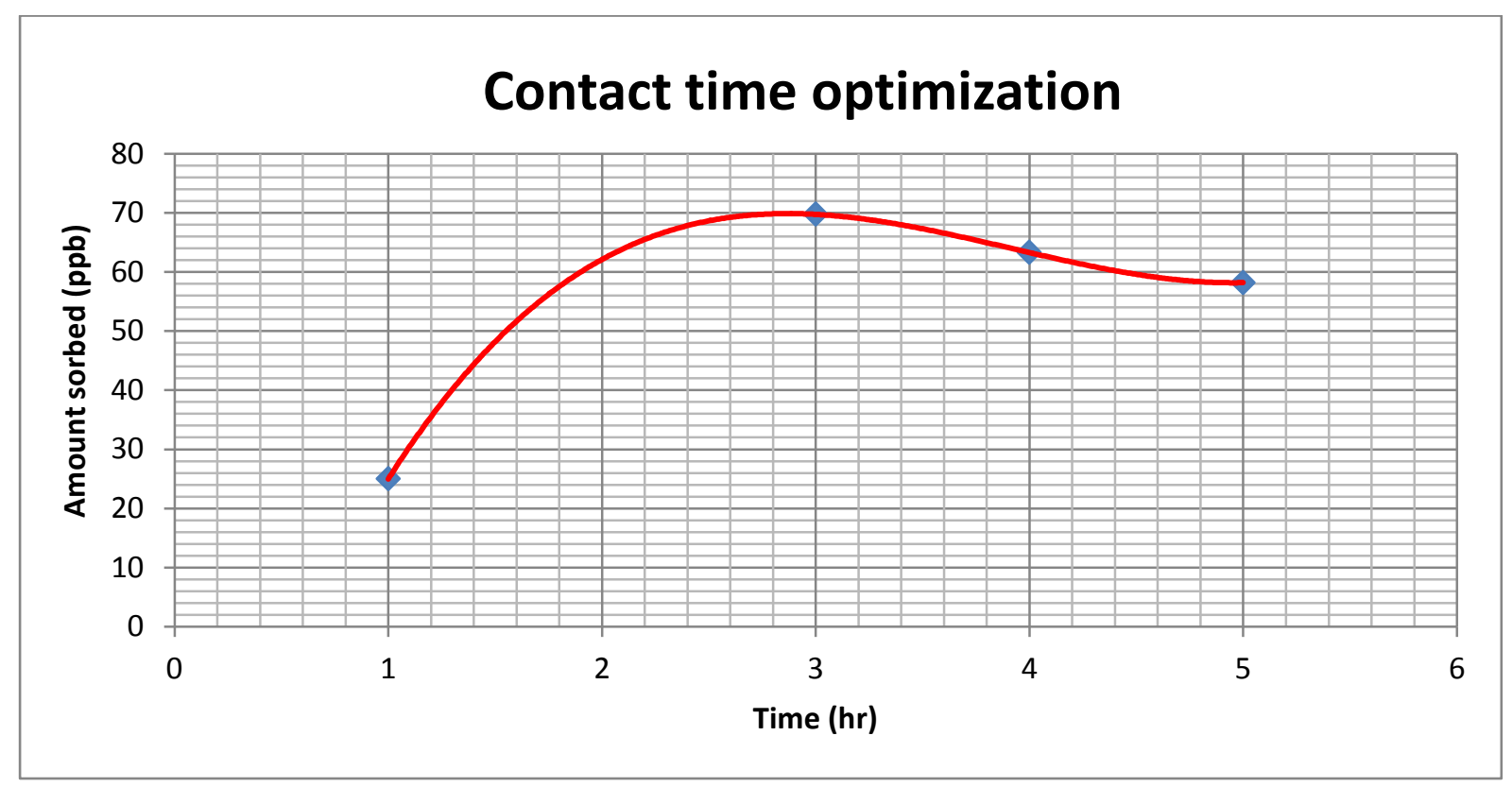

Figure S11: The amount of $\mathrm{Cu}(\mathrm{II})$ absorbed by sorbent with time at $18 \mathrm{mg} \mathrm{L}^{-1}$ sorbent. 


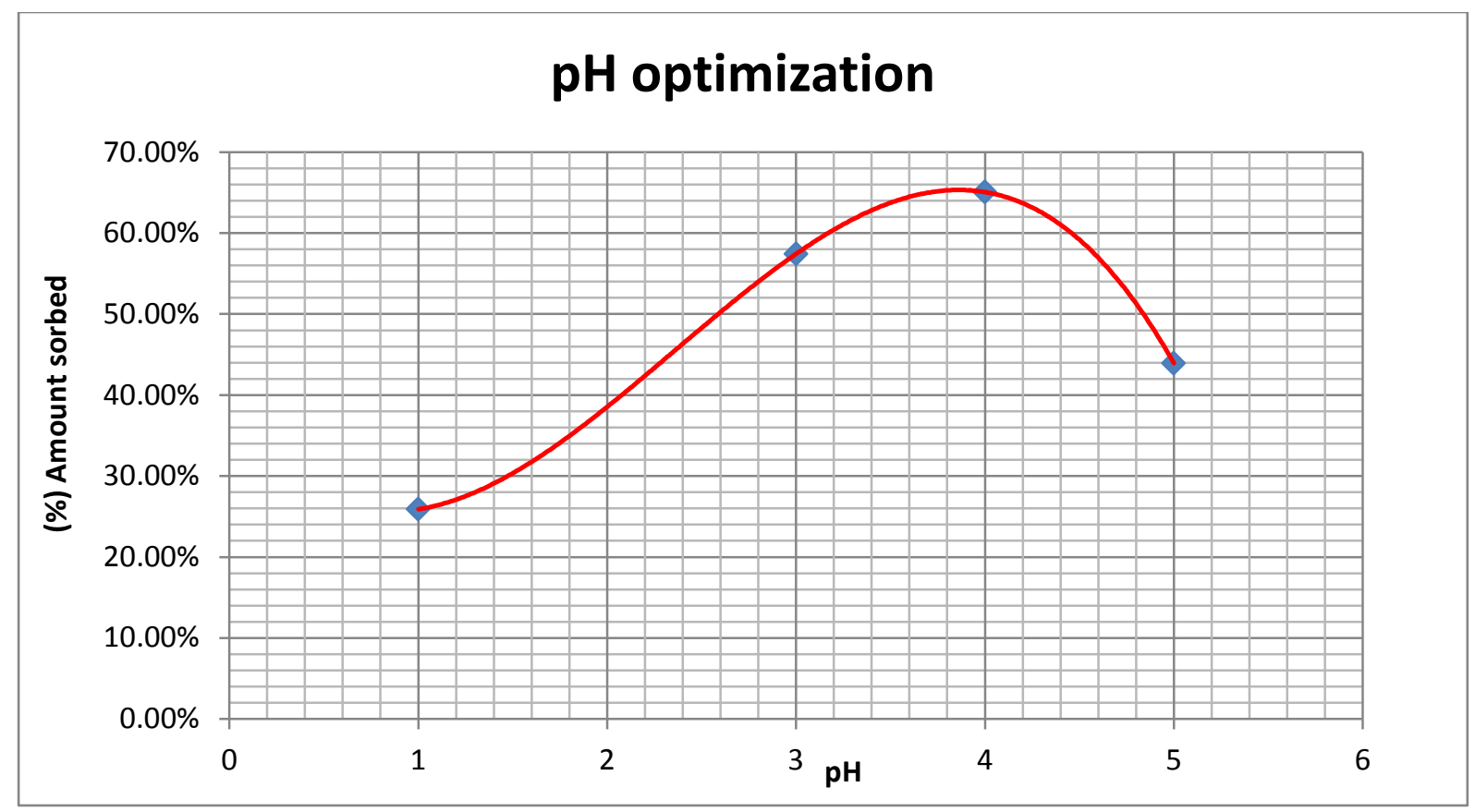

Figure S12: Sorption capacity of the $\mathrm{Cu}(\mathrm{II})$ ions when $\mathrm{pH}$ is varied. 